\title{
Size-Dependent Non-FRET Photoluminescence Quenching in Nanocomposites Based on Semiconductor Quantum Dots CdSe/ZnS and Functionalized Porphyrin Ligands
}

\author{
Eduard I. Zenkevich, ${ }^{1}$ Thomas Blaudeck, ${ }^{2,3}$ Alexander Milekhin, ${ }^{4}$ \\ and Christian von Borczyskowski ${ }^{5}$ \\ ${ }^{1}$ National Technical University of Belarus, Nezavisimosti Avenue 65, 220013 Minsk, Belarus \\ ${ }^{2}$ Institute for Print and Media Technology, University of Technology, 09107 Chemnitz, Germany \\ ${ }^{3}$ Department of Science and Technology, Organic Electronics, Linköping University, Bredgatan 34, 60174 Linköping, Sweden \\ ${ }^{4}$ Institute of Semiconductor Physics, Lavrentjev avenue 13, 630090 Novosibirsk, Russia \\ ${ }^{5}$ Center for Nanostructured Materials and Analytics, Institute of Physics, Chemnitz University of Technology, Reichenhainer Street 70, \\ 09107 Chemnitz, Germany
}

Correspondence should be addressed to Eduard I. Zenkevich, zenkev@tut.by

Received 28 March 2011; Accepted 14 June 2011

Academic Editor: Sandip Dhara

Copyright (C) 2012 Eduard I. Zenkevich et al. This is an open access article distributed under the Creative Commons Attribution License, which permits unrestricted use, distribution, and reproduction in any medium, provided the original work is properly cited.

\begin{abstract}
We review recent experimental work to utilize the size dependence of the luminescence quenching of colloidal semiconductor quantum dots induced by functionalized porphyrin molecules attached to the surface to describe a photoluminescence (PL) quenching process which is different from usual models of charge transfer (CT) or Foerster resonant energy transfer (FRET). Steady-state and picosecond time-resolved measurements were carried out for nanocomposites based on colloidal CdSe/ZnS and CdSe quantum dots (QDs) of various sizes and surfacely attached tetra-mesopyridyl-substituted porphyrin molecules ("Quantum Dot-Porphyrin" nanocomposites), in toluene at $295 \mathrm{~K}$. It was found that the major part of the observed strong quenching of QD PL in "QD-Porphyrin" nanocomposites can neither be assigned to FRET nor to photoinduced charge transfer between the QD and the chromophore. This PL quenching depends on QD size and shell and is stronger for smaller quantum dots: QD PL quenching rate constants $k_{q}$ scale inversely with the QD diameter. Based on the comparison of experimental data and quantum mechanical calculations, it has been concluded that QD PL quenching in "QD-Porphyrin" nanocomposites can be understood in terms of a tunneling of the electron (of the excited electron-hole pair) followed by a (self-) localization of the electron or formation of trap states. The major contribution to PL quenching is found to be proportional to the calculated quantum-confined exciton wave function at the QD surface. Our findings highlight that single functionalized molecules can be considered as one of the probes for the complex interface physics and dynamics of colloidal semiconductor QD.
\end{abstract}

\section{Introduction}

Semiconductor quantum dots (QD), also known as "nanocrystals," are structures with electronic and optical properties that can be engineered through the size of the structure, not just the composition. During the past decade, colloidal QDs from II-VI semiconductor materials such as CdSe have gained considerable interest due to their physical properties originating from quantum confinement [1-4]. Quantum confinement of charge carriers leads to a wide range of intriguing physical and chemical phenomena and is a new de- gree of freedom in material design. For instance, advances in the synthesis of semiconductor QDs with controllable size, shape, and optical properties as well as the hybridization of QDs with functional organic ligands make them promising materials for a diverse range of applications including photovoltaics and light emitting devices [3, 5-7], quantum computing [8], biology [9-13], and medicine [14-18].

Several concepts for the realization of QD-dye assemblies have been reported such as blends [19], substitution of surfactant molecules by appropriate dyes [20], tailored polymerdye shells [21-24], or nanoassemblies based on self-assembly 
processes [14, 25-27]. While quantum confinement is basically understood, the anchoring of functional organic molecules to tunable wide-gap semiconductor colloidal QDs using various approaches is still of considerable scientific and practical interest $[9,11,15,28-30]$, as the particular chemical composition of the surfactant shell decisively affects the photophysical properties of the assembly, especially the PL quantum yield. Colloidal QDs are bright emitters and characterized by a large absorption cross-section [2-4]. However, their photoluminescence (PL) quantum efficiency has shown to be sensitive to a number of influences that originate either from the ligand shell [22-24] or directly from the QD core [31], the QD surface [32-34], and the surrounding matrix [35].

In most cases, formation of QD-dye nanocomposites is followed by QD PL quenching, which is studied both on bulk solutions and single-particle detection level. Commonly, this $\mathrm{PL}$ quenching is interpreted as being due to photoinduced charge transfer (CT) [36-38] and/or the energy transfer processes QD $\rightarrow$ dye [39-48]. To date, though in most cases ample qualitative evidence for the presence of such quenching processes is given, only limited papers unravel quantitatively that the PL quenching (full or in some cases partly, at least) can uniquely be assigned to CT $[49,50]$ or Foerster resonance energy transfer (FRET) for bulk solutions [15, $40,41,43,51-53]$ and for single QD-dye nanocomposites $[47,48,54]$. From the other hand, PL quenching may be induced by other non-FRET processes [25, 26, 39, 42, 48, 55] as well as may be connected with the involvement of QD surface states [32-34] or the photoinduced self-trapping of charges in the dielectric medium of the environment of QDs [56]. Finally, the dynamical attachment process on QD PL efficiency in QD-dye nanocomposites may be also the reason of an additional PL quenching [57-65].

Correspondingly, from the above considerations, it turned out that in the FRET case for QD-dye nanocomposites, the direct quantitative verification of the energy transfer process as a real reason of $\mathrm{QD}$ PL quenching is the comparison of the experimental values of FRET efficiencies obtained, from one hand, via the donor (QD) PL quenching and, from the other hand, via the sensitization of the acceptor (dye or organic ligand) fluorescence. This is often missing in most publications resulting in incorrect assignments of processes and erroneous data evaluation. With these ideas in mind, here we present the detailed photophysical studies of excited states relaxation dynamics for "CdSe/ZnS QDporphyrin" nanocomposites based on steady-state and PL picosecond time-resolved measurements. The aim of this study is devoted to the quantitative analysis of FRET and non-FRET PL quenching for semiconductor CdSe and/or $\mathrm{CdSe} / \mathrm{ZnS}$ QDs of various sizes. Especially we claim that a unique and quantitative identification of FRET processes requires a detailed investigation of both the $\mathrm{QD}$ donor $\mathrm{PL}$ quenching and the dye acceptor fluorescence enhancement, since processes other than FRET and CT will cause QD photoluminescence quenching. In the result, we show that a third mechanism clearly distinct from CT or FRET may cause dye-induced PL quenching (non-FRET) and which is QD size-dependent [63] and related to the extension of the wave function of the excition to the outside of the QD [64].
Although experimental evidence for such QD PL quenching mechanisms causing PL quenching of QDs without a corresponding PL enhancement of the dye molecules attached to their surfaces was reported by Willard et al. for complexes of QDs and tetramethylrhodamine-labeled streptavidin (SAvTMR) already earlier [65], such mechanisms have not been quantitatively discussed in other publications.

\section{Experimental Methods}

Highly monodisperse CdSe and CdSe/ZnS nanocrystals (or quantum dots, QDs) capped with n-trioctylphosphine oxide (TOPO) were used in order to form semiconductor QDporphyrin heterostructures in toluene (or chloroform) at ambient temperature. The colloidal TOPO-capped CdSe and core/shell CdSe/ZnS quantum dots were obtained from Evident Technologies Inc, Troy, NY, USA. The diameters $d_{\text {CdSe }}$ of QD vary between 2.1 and $5.2 \mathrm{~nm}$, while, in most cases, two capping ZnS monolayers were applied. The molar absorption coefficients and core diameters of QDs were calculated from the first exciton absorption peak on the basis of well-proven experimental dependences between the position of the first excitonic maximum in absorption and the nanoparticle diameter [67-69]. The absorbance of the QD starting solutions was adjusted to be lower than $0.1 \mathrm{OD}$ at excitation and emission wavelengths in order to avoid nonlinear absorption and reabsorption effects. The concentrations varied in the range $(1 \div 10) \times 10^{-7} \mathrm{M}$. Stability and purity of the QD solutions were checked by measuring the quantum yield stability at least over $3 \mathrm{hrs}$ after preparation.

In our studies, $(5,10,15,20)$-tetra-meta-pyridyl-porphyrin $\mathrm{H}_{2} \mathrm{P}(\mathrm{m}-\mathrm{Pyr})_{4}$ was chosen as a probe molecule for CdSe $\mathrm{QD}$ and CdSe/ZnS core/shell QD covered with $2 \mathrm{ZnS}$ monolayers (ML) $[25,26,40,43,63,64]$. The reason was that among a series of pyridyl-substituted free-base porphyrins, $\mathrm{H}_{2} \mathrm{P}(\mathrm{m}-\mathrm{Pyr})_{4}$ was found to exhibit the most effective PL quenching of the CdSe QD upon titration. At ambient temperature in toluene solutions, the self-formation of "CdSe/ $\mathrm{ZnS}$ QD-porphyrin" nanocomposites is realized via twofold noncovalent ligating coordination $\mathrm{Zn} \cdot \cdots \mathrm{N}-\mathrm{Pyr}$ of heteroatoms $\mathrm{N}$ (in two adjacent pyridyl rings of porphyrin molecule) with $\mathrm{Zn}^{2+}$ ions (in $\mathrm{ZnS}$ core-shell QD), the same key-hole organization principle we have used earlier upon formation of self-assembled multiporphyrin complexes [7073].

Controllable formation of "CdSe/ZnS QD-porphyrin" nanocomposites has been done via multi-step titration as well as one-step (quasistatic) mixing. Titration experiments were carried out by adding to the QD solution at relative molar ratios $x=$ [porphyrin]/[QD] in toluene, thus varying the number of porphyrin molecules on the QD surface. Figure 1 shows a schematic presentation of such a hetero nanoassembly consisting of a QD with the tri- $n$-octyl phosphine oxide (TOPO) surfactant layer and one $\mathrm{H}_{2} \mathrm{P}(\mathrm{m}$ $\mathrm{Pyr})_{4}$ molecule attached via its mesopyridyl rings nearly perpendicular to the QD surface.

The absorption spectra of QD and $\mathrm{H}_{2} \mathrm{P}(\mathrm{m}-\mathrm{Pyr})_{4}$ solutions were recorded with a Shimadzu $3001 \mathrm{UV} / \mathrm{Vis}$ and Cary-500 M Varian spectrometers, and emission spectra were 


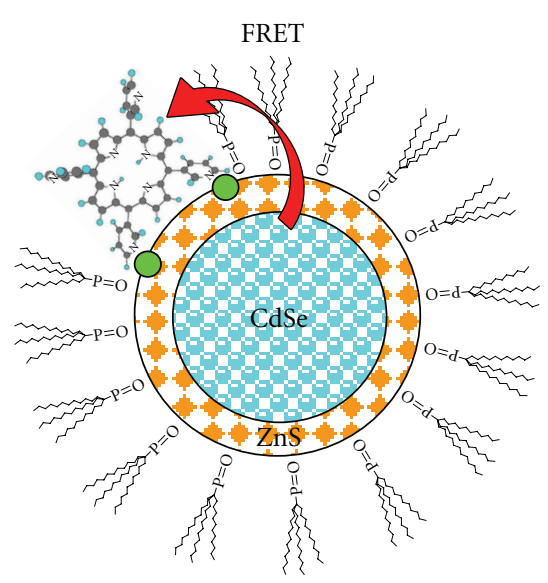

(a)

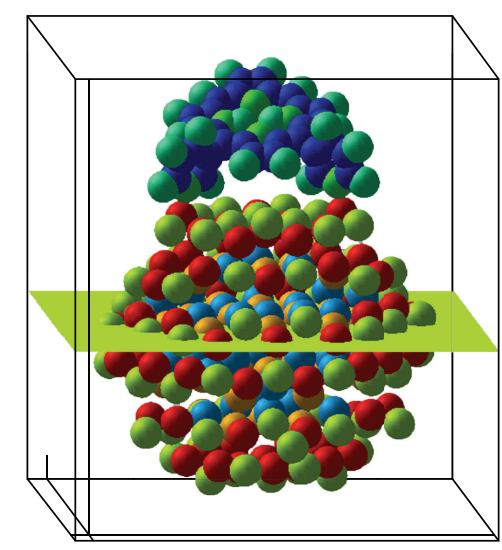

(b)

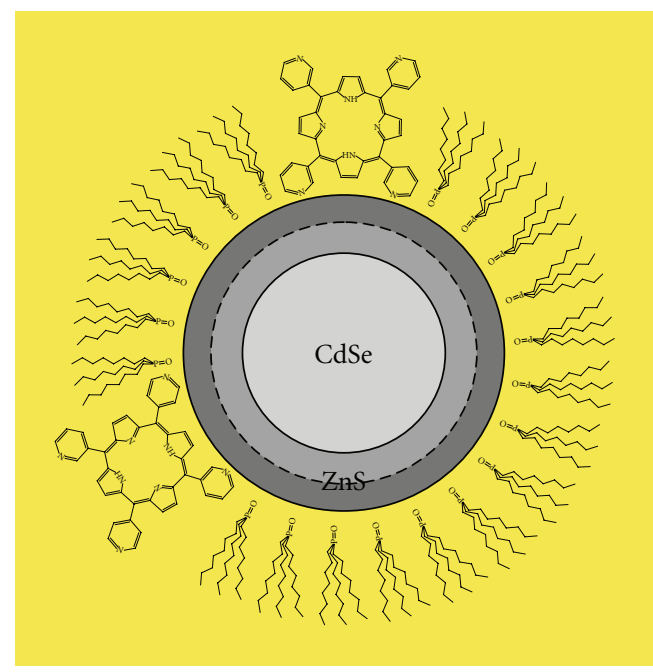

(c)

Figure 1: Schematic presentation of "QD-porphyrin" nanostructures (a) an optimized geometry for $\mathrm{Cd}_{33} \mathrm{Se}_{33}+\mathrm{H}_{2} \mathrm{P}\left(\mathrm{m}_{-} \mathrm{Pyr}\right)_{2},((\mathrm{~b})$ optimization by HyperChem 7.0; simulations by ab initio density functional theory, DFT, with the VASP code [66]) and the scales of CdSe core, $\mathrm{ZnS}$ shell, porphyrin, and TOPO molecules corresponding to relative sizes of the main components of the arrays, (c) the ZnS shell thickness for QDs was estimated on the basis of the thickness of one ZnS layer $l=5 \AA$; parameters for conical TOPO molecules $r_{\text {bottom }}=5.5 \AA$, $h_{\text {con }}=9.9 \AA ; r_{m}=7.5 \AA$ is the radius of porphyrin molecule with opposite pyridyl rings having nitrogens in metapositions, $h=10 \AA$ is the mean distance between metanitrogens of adjacent pyridyl rings (HyperChem 4.0, semiempirical method PM3).

measured with a Shimadzu RF-5001PC spectrofluorophotometer. Time-resolved photoluminescence measurements were carried out in the time-correlated single-photon counting (TCSPC) mode under right-angle geometry using homemade experimental setup $[70,71]$ based on a cavity-dumped dye laser (Spectra-Physics Models 375B and 344S) synchronously pumped by a mode-locked argon-ion laser (SpectraPhysics Model 171) for the excitation and a Peltier-cooled R3809U microchannel-plate photomultiplier tube (MCPPMT Hamamatsu) with necessary monochromator and computer photon counting board for the emission detection.

\section{Results and Discussion}

3.1. Spectral-Kinetic Experiments. Typically, the titration of CdSe/ZnS QD toluene solution by a comparable amount of mesopyridyl-substituted porphyrin molecules $\mathrm{H}_{2} \mathrm{P}(\mathrm{Pyr})_{n}$ manifests itself in the QD PL quenching (the relative intensity decrease and decay shortening $[25,26,40,43,63,64]$. This has been interpreted as being due to the formation of nanoassemblies via anchoring porphyrin ligating molecules on the $\mathrm{ZnS}$ surface. As mentioned above, the quenching efficiency and thus the probability to form "QD-porphyrin" nanocomposites scales with the number of pyridyl rings having access to the QD surfaces, being the strongest one in the case of tetrapyridyl substituted porphyrin $\mathrm{H}_{2} \mathrm{P}(\mathrm{Pyr})_{4}$. Figure 2 shows typical transformations of absorption and PL spectra of the QD solution as a function of added monomeric tetra-mesopyridyl-substituted porphyrins $\mathrm{H}_{2} \mathrm{P}(\mathrm{m}-\mathrm{Pyr})_{4}$ at well defined molar ratios $x=\left[\mathrm{H}_{2} \mathrm{P}\right] /[\mathrm{QD}]$. It is seen that upon increase of the molar ratio $x$, a linear increase of the porphyrin absorption bands takes place, whereas, in all cases, the QD absorption $\left(\lambda_{\max }=556 \mathrm{~nm}\right)$ remains constant. On the contrary, the QD PL emission (at $\lambda_{\max }=585 \mathrm{~nm}$ ) is 


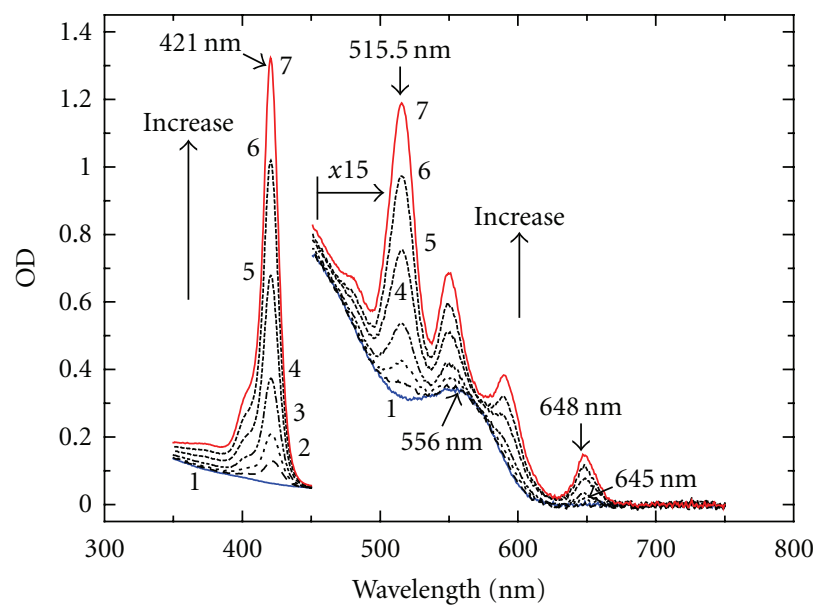

(a)

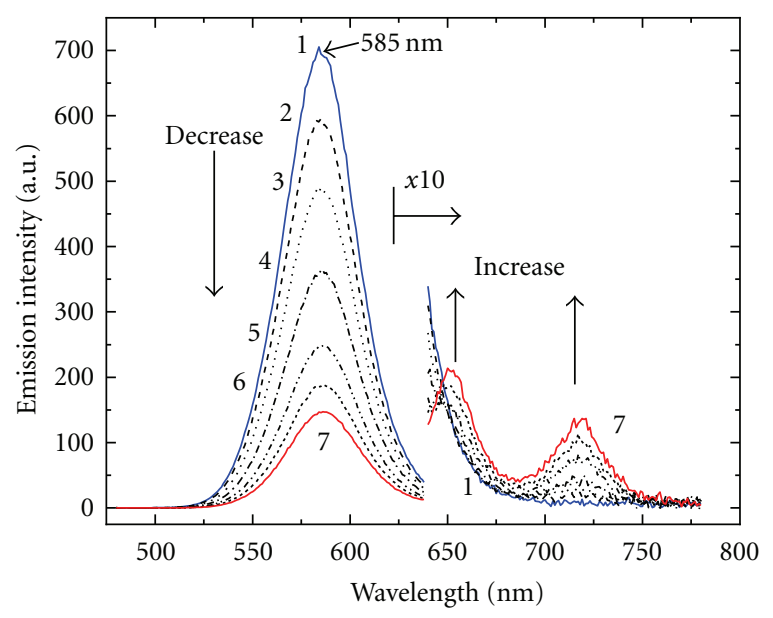

(b)

Figure 2: Absorption (a) and emission ((b), $\left.\lambda_{\mathrm{ex}}=465 \mathrm{~nm}\right)$ spectra of CdSe/ZnS QD (diameter of CdSe core $\left.d=3.8 \mathrm{~nm}\right)$ and $\mathrm{H}_{2} \mathrm{P}(\mathrm{m}-\mathrm{Pyr}){ }_{4}$ molecules in toluene at 295 upon molar ratio $x$ increase: 0.0 (1); 1.15 (2); 2.3 (3); 4.5 (4); 9.1 (5); 13.5 (6); 17.8 (7).

considerably quenched upon titration by $\mathrm{H}_{2} \mathrm{P}(\mathrm{Pyr})_{4}$ molecules. Time-resolved PL measurements show that the emission of pure QDs without porphyrin ligand is characterized by a nonexponential decay (Figure 3). The interaction with anchored porphyrin molecules manifests itself in the appearance and rise of two additional short-time components $(\sim 7 \mathrm{~ns}$ and $\sim 700 \mathrm{ps})$.

All these facts indicate that in "QD-porphyrin" nanocomposites, PL quenching of CdSe counterpart is a dynamic process caused by the increased nonradiative relaxation channels in the excited states of a nanocrystal. The increase of the solvent polarity (an addition of $32 \mathrm{vol} \%$ of polar acetone to toluene) enhances an additional decrease of QD PL by more than one order of magnitude. From typical physical reasons (mentioned in Introduction), the observed QD PL quenching may be commonly interpreted as being due to photoinduced charge transfer (CT) [36-38] and/or FRET processes QD $\rightarrow$ dye [39-48].

Usually in the FRET case, the direct verification of the energy transfer process as a real reason of PL quenching is the comparison of the experimental values of FRET efficiencies via the donor (QD) PL quenching and the sensitization of the acceptor (porphyrin) fluorescence. Correspondingly for every "QD-porphyrin" nanocomposites under study in this work, the direct comparison of quenching results for QD emission and sensitization data for porphyrin fluorescence was carried out using a complete set of titration points. Using the approach described in [22-24, 74], we estimated FRET efficiencies being obtained via sensitization effect. This estimation is based on the comparison of the absorption spectra of the QD- $\mathrm{H}_{2} \mathrm{P}$ mixture solution at every $x$ ratio with the fluorescence excitation spectra of mixed solutions and individual porphyrin $(A)$ solutions at the same molar porphyrin concentration. QD PL quenching data as well as fluorescence excitation spectra (recorded at $\lambda_{\mathrm{em}}=720 \mathrm{~nm}$ ) have been obtained at every titration step. Thus, at every titration step, FRET efficiencies $\Phi_{\mathrm{FRET}}$ have been calculated from the direct measurements of the corresponding intensities in fluorescence excitation spectra and optical densities (OD) in absorption spectra using the formula

$$
\begin{aligned}
\Phi_{\mathrm{FRET}}= & {\left[\frac{I_{D A}\left(\lambda_{\mathrm{ex}}=465 \mathrm{~nm}\right)-I_{A}\left(\lambda_{\mathrm{ex}}=465 \mathrm{~nm}\right)}{I_{A}\left(\lambda_{\mathrm{ex}}=590 \mathrm{~nm}\right)}\right] } \\
& :\left[\frac{\mathrm{OD}_{D A}(465 \mathrm{~nm})-\mathrm{OD}_{A}(465 \mathrm{~nm})}{\mathrm{OD}_{A}(590 \mathrm{~nm})}\right],
\end{aligned}
$$

where $I_{D A}$ corresponds to the porphyrin fluorescence intensity at $\lambda_{\mathrm{em}}=651 \mathrm{~nm}$ for "QD-porphyrin" nanocomposites (i.e., for mixed solutions in the presence of both QD and $\left.\mathrm{H}_{2} \mathrm{P}(\mathrm{m}-\mathrm{Pyr})_{4}\right)$, whereas $I_{A}$ is the fluorescence intensity of individual porphyrin at the same molar ratio at two different excitation wavelengths (465 and $590 \mathrm{~nm}$ ). OD are the corresponding optical densities of the solution at given molar ratio $x$. The difference $I_{D A}\left(\lambda_{\text {ex }}=465 \mathrm{~nm}\right)-I_{A}\left(\lambda_{\text {ex }}=\right.$ $465 \mathrm{~nm}$ ) reflects the increase of the acceptor emission due to FRET. $\lambda_{\text {ex }}=590 \mathrm{~nm}$ corresponds to the wavelength, where the absorption of QD is negligible.

Figure 4 presents the comparison of QD PL quenching efficiencies $I(x) / I_{0}$ and $\Phi_{\text {FRET }}$ values estimated via the porphyrin sensitization effect (1) obtained for a given "QDporphyrin" nanocomposites in all experimental range of molar ratios $x$. It is evidently seen that, at every molar ratio $x$, $\Phi_{\text {FRET }}$ values calculated from fluorescence enhancement (right scale) are significantly smaller than those estimated from QD PL quenching efficiency $\left[\Phi_{\mathrm{QUENCH}}=1-I(x) / I_{0}\right]$. In all titration range, $\Phi_{\text {FRET }}$ values are of order $6-10 \%$ and do not exceed $14-17 \%$ even at high $x$ values. It should be mentioned also that, beginning from $x>6$, there is a saturation tendency for experimental $\Phi_{\text {FRET }}$ values. Noteworthy, the same differences between $\Phi_{\mathrm{FRET}}$ values (sensitization effect) and $\Phi_{\mathrm{QUENCH}}$ efficiencies (quenching effect) have been observed for all "QD-porphyrin" nanocomposites based on $\mathrm{H}_{2} \mathrm{P}(\mathrm{m}-\mathrm{Pyr})_{4}$ porphyrin molecules and CdSe/ZnS QDs of various sizes. 


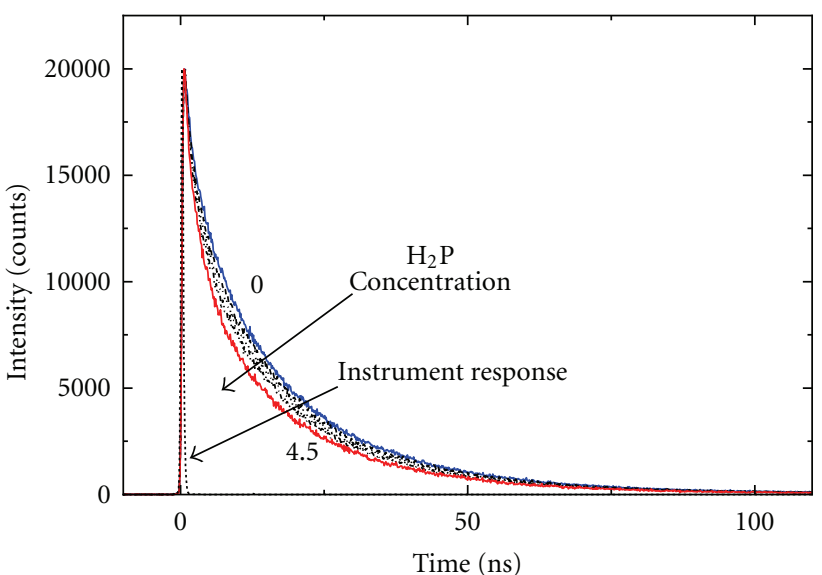

Molar ratio $x$

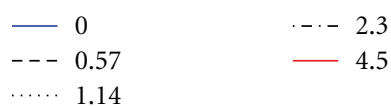

(a)

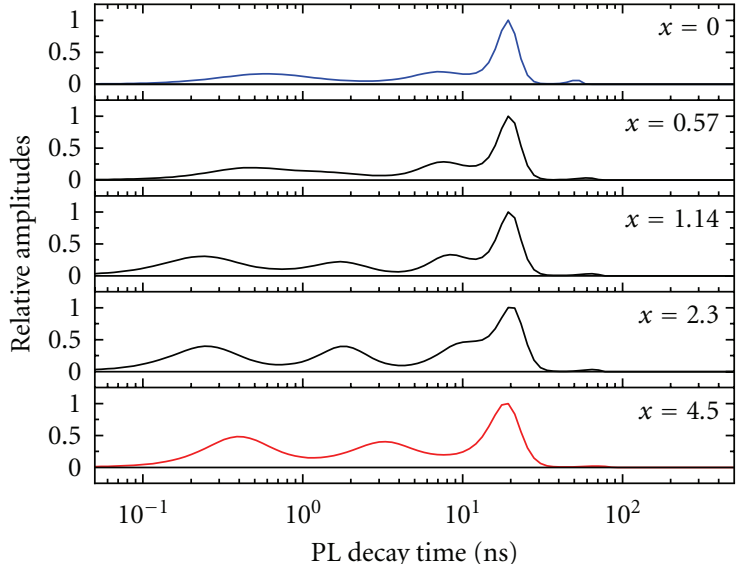

(b)

Figure 3: Time-resolved PL traces and decay amplitude distributions for CdSe/ZnS QD (diameter of CdSe core $d=3.8 \mathrm{~nm}$ ) upon molar ratio $x$ increase of $\mathrm{H}_{2} \mathrm{P}-(\mathrm{m}-\mathrm{Pyr})_{3}$ in toluene $\left(295 \mathrm{~K}, \lambda_{\mathrm{exc}}=575 \mathrm{~nm}, \lambda_{\mathrm{em}}=585 \mathrm{~nm}\right)$.

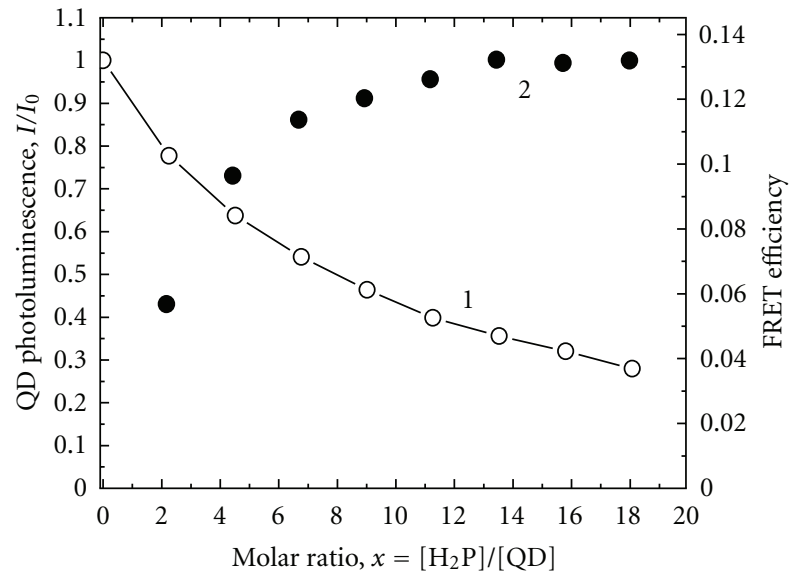

FIGURE 4: Comparison of QD PL quenching efficiencies $I / I_{0}(1$, left scale) and $\Phi_{\text {FRET }}$ values (2, right scale) estimated via the porphyrin sensitization effect for "QD-porphyrin" nanocomposites (CdSe/ZnS core diameter $d_{\mathrm{CdSe}}=3.0 \mathrm{~nm}, 2 \mathrm{ZnS}$ monolayers, $\mathrm{H}_{2} \mathrm{P}(\mathrm{m}-\mathrm{Pyr})_{4}$ porphyrin molecules) as function of the molar ratio $x=\left[\mathrm{H}_{2} \mathrm{P}(\mathrm{m}-\mathrm{Pyr})_{4}\right] /[\mathrm{QD}]$ in toluene at $295 \mathrm{~K}$.

The obtained results demonstrate clearly that FRET is not a dominant reason of QD PL quenching for "QDporphyrin" nanocomposites. In addition, for CdSe/ZnS QD of a given size ( $d_{\mathrm{CdSe}}=2.6 \mathrm{~nm}$ and $2 \mathrm{ZnS}$ monolayers), upon the replacement of $\mathrm{H}_{2} \mathrm{P}(\mathrm{m}-\mathrm{Pyr})_{4}$ molecules by $\mathrm{CuP}(\mathrm{m}-\mathrm{Pyr})_{4}$ and tetrahydro-porphyrin, THP $(\mathrm{m}-\mathrm{Pyr})_{4}$ derivatives (thus changing the overlap integral $J(\nu)=\int_{0}^{\infty} f_{D}(\nu) \varepsilon_{A}(v)\left(d \nu / \nu^{4}\right)$ values by factor of 2.5), the quenching efficiency of QD photoluminescence remains nearly the same $[26,40]$. Thus, FRET QD $\rightarrow$ porphyrin in "QD-porphyrin" nanocomposites is not the only one mechanism of the total QD PL quenching.
Nevertheless, FRET serves as indicator for the formation of the "QD-porphyrin" nanoassemblies.

From the other hand, it follows that, in the case of moderately exergonic nonadiabatic photoinduced charge (hole or electron) transfer [75], the porphyrin ligand fluorescence in "QD-porphyrin" nanocomposites should be also diminished. Nevertheless, fluorescence parameters (efficiency $\varphi_{F}$ and decay $\tau$ ) for $\mathrm{H}_{2} \mathrm{P}(\mathrm{m}-\mathrm{Pyr})_{4}$ molecules upon complexation with QDs remain the same practically with respect to those measured for individual ligands and the same conditions [40]. In addition, the comparative titrations of the same QD solutions by $\mathrm{H}_{2} \mathrm{P}(\mathrm{m}-\mathrm{Pyr})_{4}$ and $\mathrm{THP}(\mathrm{m}-\mathrm{Pyr})_{4}$ (holes acceptor) ligands as well as by $\mathrm{H}_{2} \mathrm{P}(\mathrm{m}-\mathrm{Pyr})_{2}(\mathrm{Ph})_{2}$ and electron acceptors, $\mathrm{H}_{2} \mathrm{P}(\mathrm{m}-\mathrm{Pyr})_{2}(5 \mathrm{FPh})_{2}$, or $\mathrm{H}_{2} \mathrm{P}(\mathrm{m}$ $\mathrm{Pyr}_{2}$ (Anthraquinone $)_{2}$ gives the same curves for QD photoluminescence quenching $[26,40]$. Thus, nondependence of QD PL quenching efficiency on redox properties of porphyrin ligands and the absence of the porphyrin fluorescence quenching in "QD-porphyrin" nanocomposites rule out the dominant role of usual photoinduced charge transfer processes with participation of molecular orbitals of porphyrin macrocycle in QD PL quenching for the systems under study.

Following these conclusions in mind, we put our attention on the comparative studies of PL quenching for CdSe/ZnS QDs of various sizes by attached $\mathrm{H}_{2} \mathrm{P}(\mathrm{m}$ $\mathrm{Pyr})_{4}$ molecules in all nanocomposites. It is clearly seen from Figure 5(a) that the QD relative integrated PL intensity $I / I_{0}$ decreases with increasing molar ratio $x=$ $\left[\mathrm{H}_{2} \mathrm{P}(\mathrm{m}-\mathrm{Pyr})_{4}\right] /[\mathrm{QD}]$. In addition, at the same molar ratios $x$, the observed QD PL quenching is more effective for small QD than for larger ones. In Figure 5(b) these quenching data are depicted in Stern-Volmer presentation $I_{0} / I$ versus the molar ratio $x$ which is necessary for the subsequent analysis. It is seen that Stern-Volmer plots $I_{0} / I(x)$ of these results 


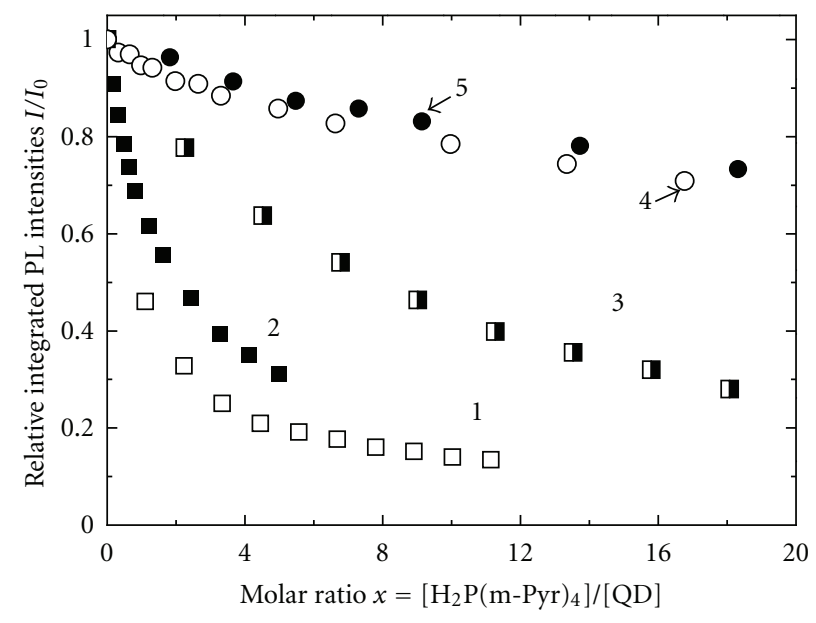

(a)

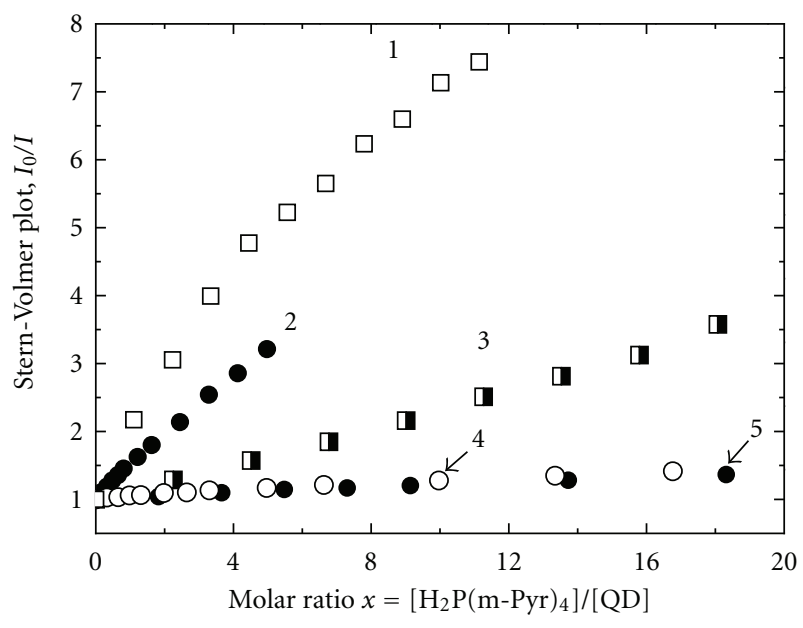

(b)

FIGURE 5: Dependences of the QD relative integrated PL intensity $I(x) / I_{0}$ (a) and corresponding Stern-Volmer plots $I_{0} / I(x)(\mathrm{b})$ on the molar ratio $x=\left[\mathrm{H}_{2} \mathrm{P}(\mathrm{m}-\mathrm{Pyr})_{4}\right] /[\mathrm{QD}]$ in titration experiments for QDs with various CdSe core diameter $\left(d_{\mathrm{CdSe}}\right)$ and number $(n)$ of ZnS monolayers: $1-d_{\mathrm{CdSe}}=3.5 \mathrm{~nm}, n=0 ; 2-d_{\mathrm{CdSe}}=2.1 \mathrm{~nm}, n=2 ; 3-d_{\mathrm{CdSe}}=3.0 \mathrm{~nm}, n=2 ; 4-d_{\mathrm{CdSe}}=4.1 \mathrm{~nm}, n=2 ; 5-d_{\mathrm{CdSe}}=5.2 \mathrm{~nm}$, $n=2$. (toluene, $295 \mathrm{~K}$ ).

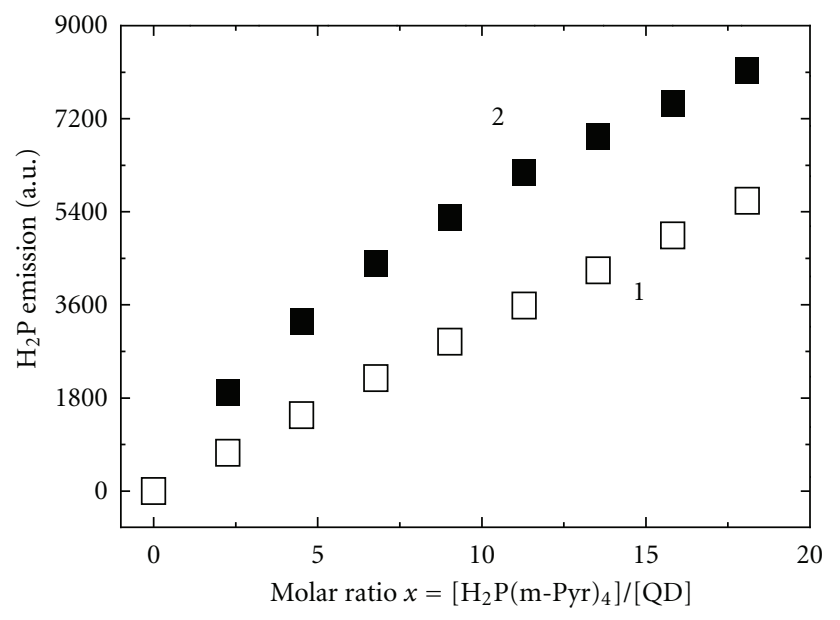

(a)

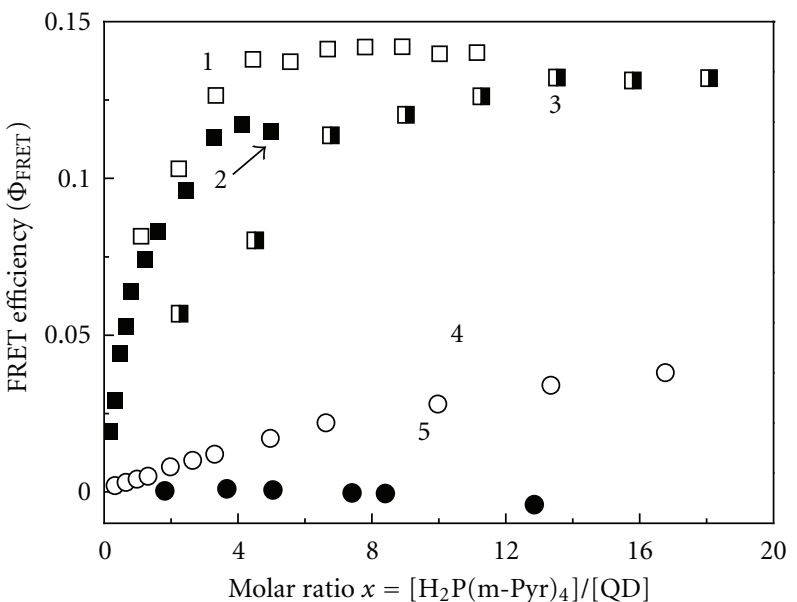

(b)

FIGURE 6: Evaluated FRET efficiencies $\Phi_{\mathrm{FRET}}$ for "QD-porphyrin" nanocomposites based on QDs with various CdSe core diameter and the same porphyrin $\mathrm{H}_{2} \mathrm{P}(\mathrm{m}-\mathrm{Pyr})_{4}$ molecules (toluene, $\left.295 \mathrm{~K}\right)$. (a) Integrated fluorescence intensity of individual $\mathrm{H}_{2} \mathrm{P}(\mathrm{m} \text { - } \mathrm{Pyr})_{4}$ molecules $(1)$ and enhanced integrated fluorescence intensity of $\mathrm{H}_{2} \mathrm{P}(\mathrm{m}-\mathrm{Pyr})_{4}$ in the presence of CdSe/ZnS QDs $\left(d_{\text {CdSe }}=3.0, n=2\right)(2)$ at the same porphyrin concentrations and excitation conditions $\left(\lambda_{\text {exc }}=465 \mathrm{~nm}\right.$ ) in both cases. (b) Experimental dependences of $\Phi_{\text {FRET }}$ efficiencies for the energy transfer QD $\rightarrow \mathrm{H}_{2} \mathrm{P}(\mathrm{m}-\mathrm{Pyr})_{4}$ on the molar ratio $x$ evaluated using data of Figure $6(\mathrm{a})$ for every nanocomposites and $(1): 1-d_{\mathrm{CdSe}}=3.5 \mathrm{~nm}$, $n=0 ; 2-d_{\text {CdSe }}=2.1 \mathrm{~nm}, n=2 ; 3-d_{\text {CdSe }}=3.0 \mathrm{~nm}, n=2 ; 4-d_{\text {CdSe }}=4.1 \mathrm{~nm}, n=2 ; 5-d_{\text {CdSe }}=5.2 \mathrm{~nm}, n=2$.

reveal a nearly linear behavior suggesting that the quenching effect per molecule is approximately constant upon variation of $x$ value during the titration experiment. Correspondingly, we will restrict our following considerations to molar ratios $x$, where these dependences are linear. This is a concentration range in which on average only a few porphyrin molecules are attached to a QD surface.

As was discussed above, QD PL quenching "QD-porphyrin" nanocomposites is due to two contributions (minor FRET and strong non-FRET). The contribution of FRET to the total PL quenching is at most $10 \%$ and hence in most cases negligible. Nevertheless, in order to analyze the main properties on the non-FRET quenching process, we have evaluated the FRET contribution in every case. FRET efficiencies $\Phi_{\text {FRET }}$ have been found using approach described in [22-24, 74] (see (1) and Figure 4). The corresponding dependences of FRET efficiencies $\Phi_{\text {FRET }}$ on the molar ratio $x$ for all QDs are shown in Figure 6. Experimental results are presented for QDs of four different CdSe core diameters with $2 \mathrm{ZnS}$ monolayers and one for uncapped CdSe, respectively. 
3.2. Analysis of $\mathrm{QD}$ Photoluminescence Quenching in " $\mathrm{QD}$ Porphyrin" Nanocomposites. For the analysis of QD PL quenching curves as a function of the number of porphyrin molecules per QD, the well known was modified. In fact more generally, PL quenching may be described in integrated form as

$$
\frac{I_{0}}{I}=1+\int_{0}^{\infty} K(x) \cdot d x .
$$

Here, $I$ and $I_{0}$ represent the QD PL intensities in presence $(I)$ and absence $\left(I_{0}\right)$ of the attached organic quencher, respectively. In this approach, the Stern-Volmer constant $K(x)$ depends explicitly on the molar ratio $x=$ $\left[\mathrm{H}_{2} \mathrm{P}(\mathrm{m}-\mathrm{Pyr})_{4}\right] /[\mathrm{QD}]$ and may be estimated from the experiment at every titration step as the first derivative of the experimental data (numerical differentiation) plotted in Stern-Volmer representation. The corresponding procedure has been carried out for all "QD-porphyrin" nanocomposites under study. Further, the Stern-Volmer function $K(x)$ is expressed by

$$
K(x)=k_{q} \cdot \tau_{0},
$$

where the variable $k_{q}$ corresponds to the total quenching rate constant induced by the attached quencher and $\tau_{0}$ to the intrinsic PL decay of alone QD in absence of porphyrin molecules. Because of nonexponential decays for QDs under study (what is typical for the most of these objects $[2-4,76]$ ), we are operating with mean values $\langle\tau\rangle$. FRET part in QD PL quenching (even minor) has been subtracted in every case.

Table 1 collects information on structural and spectralkinetic properties of CdSe and CdSe/ZnS QDs under study as well as FRET and PL quenching parameters for "QDporphyrin $\mathrm{H}_{2} \mathrm{P}(\mathrm{m}-\mathrm{Pyr})_{4}$ " nanocomposites in toluene at $295 \mathrm{~K}$. For better accuracy, the mean quenching rate constants $\left\langle k_{q}\right\rangle$ were summarized from up to four titration series for each QD size. It has been found that in the region of molar ratio of $x=0.5 \div 8$, a nearly linear behavior of Stern-Volmer plots $I_{0} / I(x)$ is observed for all QDs. Our calculations according to (3) show that in this region for every given "QD-porphyrin" nanocomposites with fixed QD size, the mean quenching $\left\langle k_{q}\right\rangle$ values remain constant but differ significantly upon CdSe core diameter $d_{\mathrm{CdSe}}$ changing or $\mathrm{ZnS}$ shell removing. As it is obvious from Table 1, the quenching rate constant $k_{q}$ characterizing non-FRET and major contribution in QD PL quenching is monotonically decreasing with the QD core diameter increase. For comparison, the CdSe QD without ZnS shell (Snapdragon Orange) shows a much stronger quenching with respect to $\mathrm{ZnS}$ core/shell QD (Hops Yellow).

As was discussed above, in case of "QD-porphyrin" nanocomposites, an effective photoinduced charge transfer leading to QD PL quenching could be excluded. For this reason, we will concentrate in the following discussion on the development of a microscopic model for that kind of PL quenching which is - with respect to attached porphyrin molecules-different from FRET or charge transfer. We have shown recently that for this QD PL specific quenching, the detailed nature of the electronic structure of the porphyrins is negligible [26, 40, 77]. Thus, we will pay our attention presumably to those aspects which are related directly to the outer interface of a QD as a function of CdSe core size and $\mathrm{ZnS}$ shell thickness.

It is known from previous experiments $[26,40,66]$ that the porphyrin molecule attaches via two lone-pair nitrogen orbitals of the pyridyl ring to the QD surface in a presumably perpendicular geometry shown in Figure 1(a) Nitrogen lonepair orbital is considered to form a coordinating bond with $\mathrm{Zn}$ or $\mathrm{Cd}$ atoms at the QD surface. Noteworthy, the attachment of pyridine molecule via one nitrogen orbital to QD at the same molar ratio does not manifest in a noticeable PL quenching with respect to pyridyl substituted porphyrins [40]. We apt to believe that the inductive and mesomeric effects (leading to the bond polarization and electronic density shifts [78]) are characteristic, namely, for pyridyl substituted porphyrin macrocycles (discussed in [40]) and may lead to the formation of specific sites on QD surface at interface [79]. This distortion of the charge distribution corresponds to the creation of an "effective" charge seen by the exciton and will enhance the nonradiative decay of excitons, showing up as PL quenching or a reduced quantum efficiency. We borrow from currently accepted blinking models [80] the idea that a charging of a QD (or molecule) is the major source of both PL intermittency and PL quenching. In the result, at the outer interface of "QD-porphyrin" nanocomposites, two contributions seem to be important: (i) the presence of specific "binding" sites with a distortion of the charge distribution capable to trap exciton and (ii) the evanescent wave function of the confined exciton "leaking" out of the core (and the $\mathrm{ZnS}$ shell) of the QD.

With respect to QDs, it is well known $[2,4,81,82]$ that quantum confinement of the excitonic wave function in its most simple version confines the wave function of the exciton (electron-hole pair) to a spherical box. As in any related quantum mechanical problem, the wave function may extend beyond the imposed barrier or, in other words, the corresponding particle may tunnel through the barrier. Considering hole and electron independently, as the confinement for the latter is much smaller due to its lower effective mass, we may safely assume that the tunneling probability for the electron is higher as compared to the hole. Thus, the following considerations are limited to the behavior of the electron wave function, especially, at the interface between the QD and the functional mesopyridyl group of the attached porphyrin macrocycle.

The general ideas of our model and calculation results are depicted in Figure 7(a). In addition to the coordination of a mesopyridyl ring to the surface, the electron wave function at the QD outer interface is schematically shown. Imposed by the porphyrin attached to the surface, the electron wave function is locally perturbed due to the specific attachment of mesopyridyl-substituted porphyrin (i.e., the (presence of the nitrogen lone-pair orbital forming a surface state subsequently trapping the electron of the photogenerated exciton). It is assumed that the particular influence of the nitrogen lone-pair to be independent of the QD size.

It follows from above considerations that all observed size dependence of the PL quenching (as expressed by the 


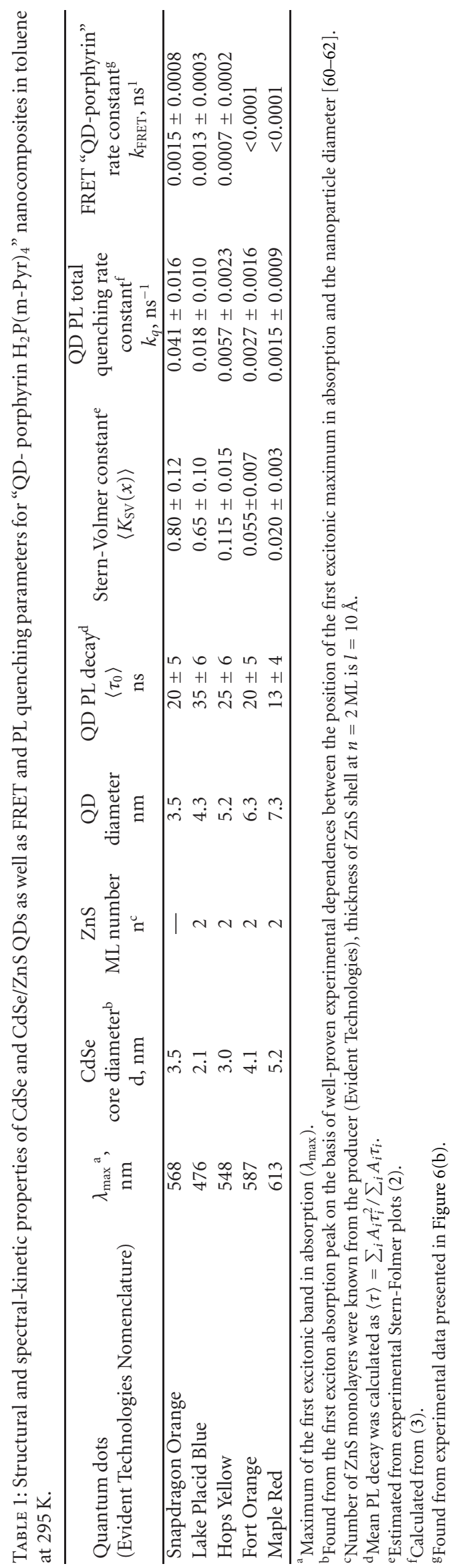




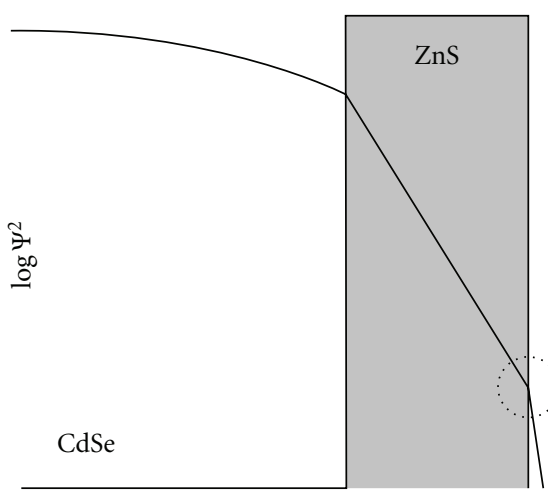

(a)
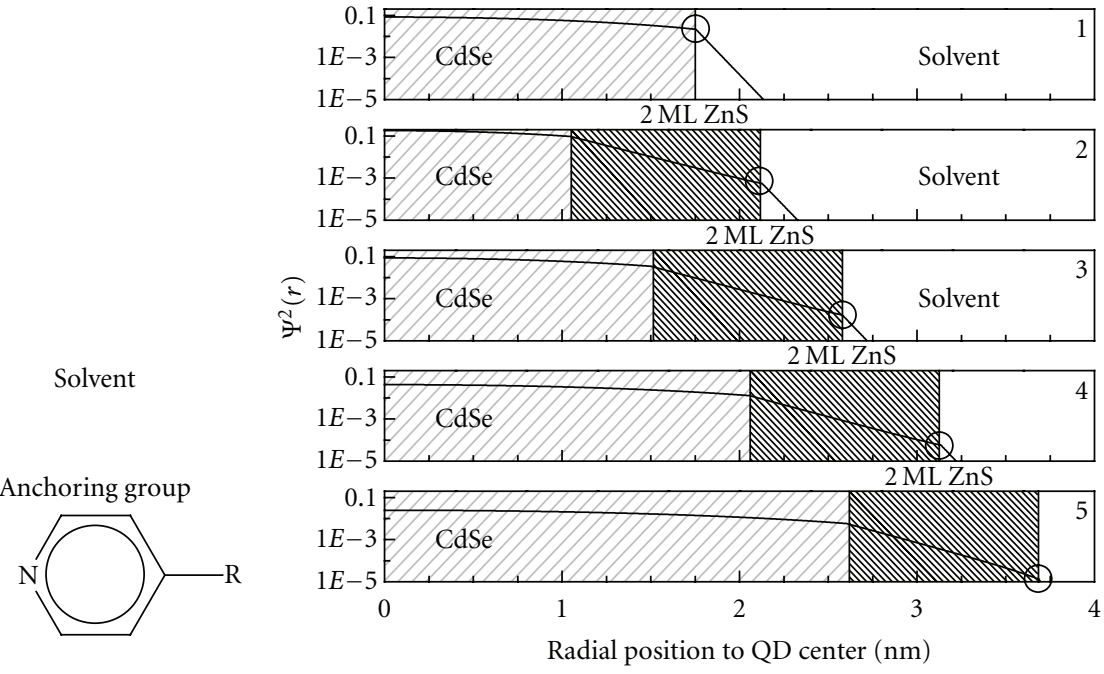

(b)

FIGURE 7: Scheme of QD PL quenching model. (a) Scheme of the electron delocalization in the excited CdSe/ZnS QD being attached with mesopyridyl-substituted porphyrin molecule. Upon excitation, an electron-hole pair (exciton) is created in the QD CdSe core. The electron is delocalized over the core and the $\mathrm{ZnS}$ shell. As a result of the finite $\mathrm{ZnS}$ energy barrier $E_{\mathrm{ZnS}}$, the electron can tunnel to the $\mathrm{ZnS}$ surface (and to the environment). Upon interaction with the lone-pair of a pyridyl group of a porphyrin molecule, the electron becomes partly localized in the vicinity of the attachment site. (b) Calculated radial part of the probability density function $\psi^{2}(r)$ for $1 \mathrm{~s} \mathrm{electron} \mathrm{in} \mathrm{a} \mathrm{multi}$ shell spherical potential for five QDs of different sizes: $1-d_{\text {CdSe }}=3.5 \mathrm{~nm}, n=0 ; 2-d_{\text {CdSe }}=2.1 \mathrm{~nm}, n=2 ; 3-d_{\text {CdSe }}=3.0 \mathrm{~nm}, n=2$; $4-d_{\mathrm{CdSe}}=4.1 \mathrm{~nm}, n=2 ; 5-d_{\mathrm{CdSe}}=5.2 \mathrm{~nm}, n=2$ (calculation details are presented in the text).

quenching rate constants $k_{q}$ in Table 1) may be directly related to the squared amplitude of the electron wave function at the interface for QD of every size. Correspondingly, the calculation of changes of charge densities therefore reduces to an evaluation of the radial probability function $r^{2} \psi^{2}(r)$ for the electron as a function of the CdSe core diameter and $\mathrm{ZnS}$ shell thickness. To account for the local character of this interaction at $r=R+D$, where $R=1 / 2 d_{\text {Cdse }}$ corresponds to the QD core radius and $D$ to the $\mathrm{ZnS}$ shell thickness, respectively, $r^{2} \psi^{2}(r)$ has to be normalized with respect to $r^{2}$, that is, with respect to the total QD surface area. This approximation holds since only point-like interactions at the position of one nitrogen lone-pair orbital are considered in this case. In particular, for the quantitative calculation of $\psi^{2}(r)$, we have applied the particle-in-a-box model solving the Schrödinger equation for an idealized QD with respect to the confinement eigen energies [82]. In this model, the effective mass $m_{a}^{*}$ is assumed to be a material parameter which is a function of the radius $R$. As it has been done in $[81,82]$, the single-carrier envelope wave functions $\psi_{a}$ in a spherical core/shell QD were calculated using the Schrödinger equation

$$
\left(\frac{\hbar^{2}}{2} \frac{\partial^{2}}{\partial r^{2}}\left(\frac{1}{m_{a}^{*}(r)}+V_{a}(r)\right)\right) \psi_{a}=E_{a} \psi_{a}
$$

Here, the index $a=e, h$ represents electron and hole, respectively. Solutions were obtained by applying continuity relations for the single-carrier wave functions at the interfaces between the CdSe core $(i=1), \mathrm{ZnS}$ shell $(i, j=2)$, and matrix $(j=2)$, respectively, by assuming

$$
\begin{aligned}
\psi_{i}\left(r_{j i}\right) & =\psi_{j}\left(r_{j i}\right), \\
\left.\frac{1}{m_{i}^{*}} \frac{d}{d r} \psi_{i}(r)\right|_{r=r_{j i}} & =\left.\frac{1}{m_{j}^{*}} \frac{d}{d r} \psi_{j}(r)\right|_{r=r_{j i}} .
\end{aligned}
$$

The Schrödinger equation was numerically integrated by means of an ordinary-differential-equation (ODE) solver tool for java (RK 4/5 MultiStep) available via OpenSourcePhysics [83]. The ODE solver tool was based on a 4/5order Runge-Kutta algorithm with variable step width. The results were verified with a second-order Runge-Kutta algorithm implemented in Fortran. Technically, the calculation resembled a shooting method which allows the calculation of wave functions in a one-dimensional or radially symmetric potential landscapes. For the calculations of $\psi^{2}(r)$, the following parameters were used: energy barriers of $2 \mathrm{eV}$ for the CdSe/ZnS interface [84] and $4 \mathrm{eV}$ for the ZnS/matrix interface [81], and relative effective electron masses of 0.13 , 0.52 and 1.00 in the CdSe core, in the confined ZnS shell, and in the surrounding matrix, respectively $[4,85]$. We assumed a 1s-wavefunction confined in QD. For an even function like $1 \mathrm{~s}$, PSI $1=1$ and PSI2 $=1$ are given. The core of a shooting method is the value of the wave function at radial position PSIn +2 is calculated from the values at PSIn +1 and PSIn. Accounting for the discontinuities at the interfaces, the calculation of PSIn +2 was altered to (6) whenever an interface was reached. 


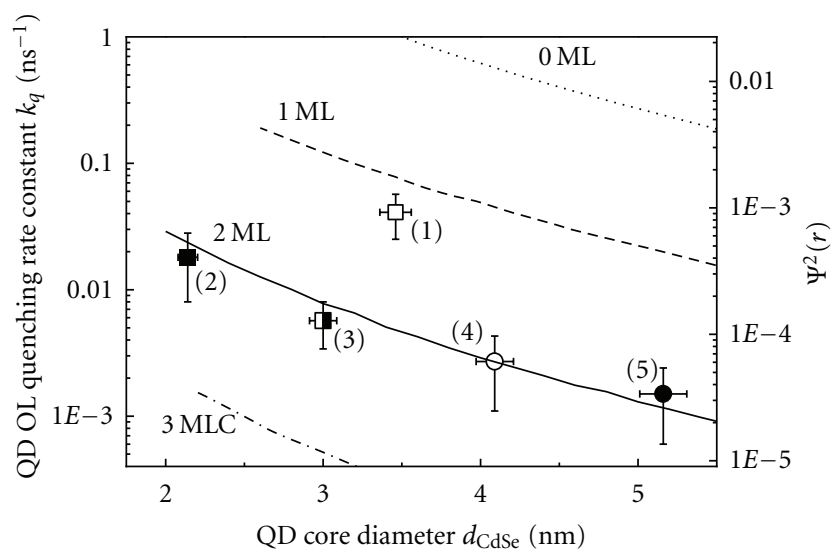

FIGURE 8: Comparison of the experimentally determined quenching rate constants $k_{q}$ with respect to the calculated $\psi^{2}(r)$ values for "QD-porphyrin" nanocomposites in toluene at $295 \mathrm{~K}$. (Left axis) Averaged (for molar ratios $x=0.5 \div 8$ ) quenching rate constant $k_{q}$ for QD PL quenching induced by attached $\mathrm{H}_{2} \mathrm{P}(\mathrm{m}-\mathrm{Pyr})_{4}$ molecules for one uncapped (open marker) and four ZnS-capped (solid markers) CdSe QD. $2 R=d_{\text {CdSe }}$ corresponds to the CdSe core diameter and $D$ to the ZnS ML thickness. (Right axis) Calculated sizedependent curves for the probability density functions $\psi^{2}(r=R+$ $D)$ of a $1 \mathrm{~s}$ electron at the outer interface $(r=R+D)$ between the $\mathrm{ZnS}$ shell and the environment for various $\mathrm{ZnS}$ shell thicknesses $D$ for a potential barrier energy of $2 \mathrm{eV}$ between the CdSe core and the $\mathrm{ZnS}$ shell, and a barrier energy of $4 \mathrm{eV}$ between the $\mathrm{ZnS}$ shell and the matrix. The constant $C$ (see (7)) has been adjusted with respect to $\psi^{2}(R+D)$ to fit the experimental value for QD with $d_{\mathrm{CdSe}}=4.1 \mathrm{~nm}$ and the number of $\mathrm{ZnS}$ monolayers $n=2 \mathrm{ML}$. QD parameters: $1-d_{\text {CdSe }}=3.5 \mathrm{~nm}$, number of $\mathrm{ZnS}$ monolayers $n=0 ; 2-d_{\mathrm{CdSe}}=2.1 \mathrm{~nm}, n=2 ; 3-d_{\mathrm{CdSe}}=3.0 \mathrm{~nm}, n=2 ; 4-$ $d_{\mathrm{CdSe}}=4.1 \mathrm{~nm}, n=2 ; 5-d_{\mathrm{CdSe}}=5.2 \mathrm{~nm}, n=2$.

Figure 7(b) shows the calculated $\psi^{2}(r)$ values of an $s$-type electron wave function for four CdSe/ZnS QDs with $n=2$ $\mathrm{ZnS}$ monolayers and one CdSe QD without a $\mathrm{ZnS}$ monolayers. It can be evidently seen that $\psi^{2}(r)$ becomes smaller at the outer interface (marked by a circle) upon increasing QD diameter. The corresponding value is largest for the uncapped CdSe QD $(R=1.8 \mathrm{~nm})$. Our results are quantitatively in close agreement with other calculations [35] considering solvent effects upon optical band gap energies. We can, however, neglect direct contributions to the band gap, since we did not observe any spectral shifts of the PL upon assembly formation $[25,26,40,77]$. Then, correspondingly, the calculated $\psi^{2}(r)$ values for every QD may be directly compared to the observed size dependence of the QD PL quenching for "QD-porphyrin" nanocomposites (as expressed by the quenching rate $k_{q}$ in Table 1 ). This comparison may be presented as follows:

$$
k_{q}(r)=C \psi^{2}(r) .
$$

It should be noted in this respect that the constant $C$ contains all specific properties of the binding process and cannot be determined quantitatively in our model. In case that the interaction of the chromophore at the interface may not be approximated by a point-like interaction, the constant
$C$ in (7) should be modified to $C=A / 4 \pi r^{2}$, where $A$ corresponds an "effective molecular interaction area".

Correspondingly, Figure 8 shows the comparison of the experimentally determined quenching rate constants $k_{q}$ with respect to the calculated $\psi^{2}(r)$ values both as a function of the QD core diameter $2 R$ and the number of $\mathrm{ZnS}$ monolayers. The theoretical lines correspond to calculated $\psi^{2}(r)$ values shown in Figure 7(b), with one and the same proportionality constant $C$ determined in a way that the theoretical predictions for all QD capped with 2 monolayers $\mathrm{ZnS}$ agree with the experimental values most closely. It is clearly seen that experimental quenching rate constants $k_{q}$ follow closely the calculated $\psi^{2}(r)$ behavior for all nanocomposites based on QDs having $n=2 \mathrm{ZnS}$ monolayers. Thus, this good coincidence between size-dependent PL quenching rate constants and calculated amplitudes of the exciton wave function supports strongly our model that a well defined chromophore-induced surface quenching mechanism other than FRET and/or photoinduced charge transfer is the main reason for QD PL quenching in "QD-porphyrin" nanocomposites. In fact, the dependence of QD PL quenching on the QD size and ZnS shell thickness (induced by only one single mesopyridyl porphyrin molecule at low molar ratios) clearly resembles the tunneling of an electron (through the $\mathrm{ZnS}$ barrier) to the outer interface of the QD. Such tunneling is followed by the (self-) localization of the electron-hole pair (due to inductive and mesomeric effects) which opens new nonradiative channels via enhanced electron-photon coupling. The consequence is that the quantum efficiency of the subsequently photogenerated exciton will be reduced. Correspondingly, fluctuating bond formations at the QD surface (followed by changes in local charge densities or formation of surface states) result in fluctuating quantum efficiencies of the QD which are closely related to lifetime fluctuations and blinking observed for single quantum dots $[86,87]$.

Additionally, data presented in Figure 8 show that in spite of our model works well for capped CdSe/ZnS QDs, the quenching rate constant $k_{q}$ for the uncapped CdSe (point 1 ) is experimentally below the theoretically predicted $\psi^{2}(r)$ value. The reason for that might be twofold. (i) Due to differences in the binding constant of the chromophore, the $\mathrm{Cd} \cdots \mathrm{N}$ coordination is supposed to be weaker than a $\mathrm{Zn} \cdots \mathrm{N}$ one and thus the average number of porphyrins attached to the surface will be smaller which will be accompanied by a reduced quenching. This implies that we have as compared to $\mathrm{ZnS}$ capping to consider a smaller molar ratio $x$. In case we would be able to correct for this quantitatively, $K(x)$ would increase towards values imposed by our model calculations. (ii) Calculating $\psi^{2}(r)$ depends critically on the respective barrier energies at the interface, which are not known with high accuracy.

Finally, the central interpretation of QD PL quenching in "QD-porphyrin" nanocomposites is that already one or a few point-like charge density modifications in the surfactant layer (composed of ligands and the attached chromophore with specific $\pi$-electron distribution) will lead to local energy minima that force one of the charge carriers of the exciton to become localized. The participation of localized charges 
is strongly supported by the observation that porphyrininduced PL quenching significantly increases upon increase of the polarity of the solvent [88]. In addition, previous nanosecond time-resolved PL experiments show that, upon formation of nanoassemblies (in which only a few porphyrins are involved), the overall reduction of the quantum efficiency is accompanied by a shift of the nonexponential PL decay kinetics towards shorter decay times $[26,88]$. We like to stress again that the presently discussed mechanism for QD PL quenching is completely distinct from the known mechanism of the photoinduced charge transfer between interacting inorganic and organic counterparts.

\section{Conclusions}

We could prove the complexation of tetra-mesopyridyl-substituted porphyrin molecules, $\mathrm{H}_{2} \mathrm{P}(\mathrm{Pyr})_{4}$ to $\mathrm{CdSe} / \mathrm{ZnS}$ or CdSe QD surface by steady-state titration and time-resolved fluorescence measurements. At $295 \mathrm{~K}$, the formation of "QDporphyrin" nanocomposites manifests itself in the QD PL quenching (the relative intensity decrease and decay shortening). At the same molar ratios $x=\left[\mathrm{H}_{2} \mathrm{P}(\mathrm{m}-\mathrm{Pyr})_{4}\right] /[\mathrm{QD}]$, the quenching is more effective for small QDs than for larger ones. It follows from experimental Stern-Volmer PL quenching plots $I_{0} / I(x)$ and quantum mechanical calculations for the electron wave functions that the specificity of the exciton nonradiative decay in "QD-porphyrin" nanocomposites is due to the charge tunneling through $\mathrm{ZnS}$ barrier in quantum confinement conditions. We have shown quantitatively that a third mechanism clearly distinct from Foerster resonant energy transfer (FRET) and the photoinduced charge transfer between the QD and the chromophore may cause the ligandinduced QD PL quenching (the so-called non-FRET). These observations are in line with the microscopic understanding of blinking phenomena of single QD. The experimental findings and conclusions done on their basis highlight that single functionalized molecules can be considered as one of the probes for the complex interface physics and dynamics of colloidal semiconductor QD. The presented results should be taken into account upon the development of nanosensors based on semiconductor CdSe QDs and organic analytes of various types.

\section{Acknowledgments}

Tetra-mesopyridyl-substituted porphyrin has been synthesized and characterized by Dr. A. M. Shulga (B. I. Stepanov Institute of Physics, National Academy of Sciences, Minsk, Belarus). We thank Professor Dr. S. V. Gaponenko (B. I. Stepanov Institute of Physics, National Academy of Sciences, Minsk, Belarus) for fruitful discussion. This paper is in part based on experimental results contributed by Professor Dr. F. Cichos (Leipzig University, Germany) and Dr. E. Petrov (Dresden University of Technology, Germany). The programming code in OpenSourcePhysics was implemented by M. Heidernätsch, M. S. (Chemnitz University of Technology). This work was funded by the German Science Foundation (Graduate College 826 "Accumulation of Single
Molecules to Nanostructures"), the Volkswagen Foundation (Priority Program "Physics, Chemistry, and Biology with Single Molecules"), the Belarussian State Program for Scientific Research "Convergence 3.2.08-Photophysics of Bioconjugates, Semiconductor, and Metallic Nanostructures and Supramolecular Complexes and Their Biomedical Applications", and BRFFR Grant no. Ф10CO-005.

\section{References}

[1] A. P. Alivisatos, "Semiconductor clusters, nanocrystals, and quantum dots," Science, vol. 271, no. 5251, pp. 933-937, 1996.

[2] V. Klimov, Nanocrystall Quantum Dots, CRS Press LLC, Washington, DC, USA, 2010.

[3] A. L. Rogach, Ed., Semiconductor Nanocrystal Quantum Dots (Synthesis, Assembly, Spectroscopy and Applications), Springer, Wien, Austria, 2008.

[4] S. V. Gaponenko, Optical Properties of Semiconductor Nanocrystals, Cambridge University Press, Cambridge, UK, 2005.

[5] I. Gur, N. A. Fromer, C. P. Chen, A. G. Kanaras, and A. P. Alivisatos, "Hybrid solar cells with prescribed nanoscale morphologies based on hyperbranched semiconductor nanocrystals," Nano Letters, vol. 7, no. 2, pp. 409-414, 2007.

[6] R. Kniprath, J. P. Rabe, J. T. McLeskey, D. Wang, and S. Kirstein, "Hybrid photovoltaic cells with II-VI quantum dot sensitizers fabricated by layer-by-layer deposition of watersoluble components," Thin Solid Films, vol. 518, no. 1, pp. 295-298, 2009.

[7] L. Liu, J. Hensel, R. C. Fitzmorris, Y. Li, and J. Z. Zhang, "Preparation and photoelectrochemical properties of CdSe/TiO2 hybrid mesoporous structures," Journal of Physical Chemistry Letters, vol. 1, no. 1, pp. 155-160, 2010.

[8] J. R. Petta, A. C. Johnson, J. M. Taylor et al., "Applied physics: coherent manipulation of coupled electron spins in semiconductor quantum dots," Science, vol. 309, no. 5744, pp. 2180 2184, 2005.

[9] M. De, P. S. Ghosh, and V. M. Rotello, "Applications of nanoparticles in biology," Advanced Materials, vol. 20, no. 22, pp. 4225-4241, 2008.

[10] R. Gill, M. Zayatz, and I. Wilner, "Halbleiterquantenpunkte für die bioanalyse," Angewandte Chemie, vol. 120, no. 40, pp. 7714-7736, 2008.

[11] M. F. Frasco, V. Vamvakaki, and N. Chaniotakis, "Porphyrin decorated CdSe quantum dots for direct fluorescent sensing of metal ions," Journal of Nanoparticle Research, vol. 12, no. 4, pp. 1449-1458, 2010.

[12] B. Zhang, X. Liang, L. Hao et al., "Quantum dots/particlebased immunofluorescence assay: synthesis, characterization and application," Journal of Photochemistry and Photobiology $B$, vol. 94, no. 1, pp. 45-50, 2009.

[13] M. McDowell, A. E. Wright, and N. I. Hammer, "Semiconductor nanocrystals hybridized with functional ligands: new composite materials with tunable properties," Materials, vol. 3, no. 1, pp. 614-637, 2010.

[14] A. C. S. Samia, S. Dayal, and C. Burda, "Quantum dot-based energy transfer: perspectives and potential for applications in photodynamic therapy," Photochemistry and Photobiology, vol. 82, no. 3, pp. 617-625, 2006.

[15] J. M. Tsay, M. Trzoss, L. Shi et al., "Singlet oxygen production by peptide-coated quantum dot-photosensitizer conjugates," Journal of the American Chemical Society, vol. 129, no. 21, pp. 6865-6871, 2007. 
[16] J. Ma, J. Y. Chen, M. Idowu, and T. Nyokong, "Generation of singlet oxygen via the composites of water-soluble thiolcapped CdTe quantum dots-sulfonated aluminum phthalocyanines," Journal of Physical Chemistry B, vol. 112, no. 15, pp. 4465-4469, 2008.

[17] P. Juzenas, W. Chen, Y. P. Sun et al., "Quantum dots and nanoparticles for photodynamic and radiation therapies of cancer," Advanced Drug Delivery Reviews, vol. 60, no. 15, pp. 1600-1614, 2008.

[18] A. Rakovich, T. Rakovich, V. Kelly et al., "Photosensitizer methylene blue-semiconductor nanocrystals hybrid system for photodynamic therapy," Journal of Nanoscience and Nanotechnology, vol. 10, no. 4, pp. 2656-2662, 2010.

[19] M. Anni, L. Manna, R. Cingolani, D. Valerini, A. Cretí, and M. Lomascolo, "Förster energy transfer from blue-emitting polymers to colloidal CdSe/ZnS core shell quantum dots," Applied Physics Letters, vol. 85, no. 18, pp. 4169-4171, 2004.

[20] M. Sykora, M. A. Petruska, J. Alstrum-Acevedo, I. Bezel, T. J. Meyer, and V. I. Klimov, "Photoinduced charge transfer between CdSe nanocrystal quantum dots and Ru-polypyridine complexes," Journal of the American Chemical Society, vol. 128, no. 31, pp. 9984-9985, 2006.

[21] I. Potapova, R. Mruk, C. Hübner, R. Zentel, T. Basché, and A. Mews, "CdSe/ZnS nanocrystals with dye-functionalized polymer ligands containing many anchor goups," Angewandte Chemie, vol. 117, pp. 2490-2493, 2005.

[22] A. R. Clapp, I. L. Medintz, J. M. Mauro, B. R. Fisher, M. G. Bawendi, and H. Mattoussi, "Fluorescence resonance energy transfer between quantum dot donors and dye-labeled protein acceptors," Journal of the American Chemical Society, vol. 126, no. 1, pp. 301-310, 2004.

[23] A. J. Morris-Cohen, M. D. Donakowski, K. E. Knowles, and E. A. Weiss, "The effect of a common purification procedure on the chemical composition of the surfaces of CdSe quantum dots synthesized with trioctylphosphine oxide (TOPO)," Journal of Physical Chemistry C, vol. 114, no. 2, pp. 897-906, 2010.

[24] K. E. Knowles, D. B. Tice, E. A. McArthur, G. C. Solomon, and E. A. Weiss, "Chemical control of the photoluminescence of CdSe quantum dot-organic complexes with a series of psubstituted aniline ligands," Journal of the American Chemical Society, vol. 132, no. 3, pp. 1041-1050, 2010.

[25] E. I. Zenkevich, A. M. Shulga, T. Blaudeck, F. Cichos, and C. von Borczyskowski, "Physics, chemistry and applications of nanostructures," in Reviews and Short Notes to Nanomeeting, V. I. Borisenko, S. V. Gaponenko, and V. S. Gurin, Eds., vol. 367, p. 367, World Scientific, Singapore, 2005.

[26] E. I. Zenkevich, T. Blaudeck, A. M. Shulga, F. Cichos, and C. von Borczyskowski, "Identification and assignment of porphyrin-CdSe hetero-nanoassemblies," Journal of Luminescence, vol. 122-123, no. 1-2, pp. 784-788, 2007.

[27] T. C. Lim, V. J. Bailey, Y. P. Ho, and T. H. Wang, "Intercalating dye as an acceptor in quantum-dot-mediated FRET," Nanotechnology, vol. 19, no. 7, Article ID 075701, 2008.

[28] A. De La Escosura-Muñiz, C. Parolo, and A. Merkoi, "Immunosensing using nanoparticles," Materials Today, vol. 13, no. 78, pp. 24-34, 2010.

[29] M. Wang, S. J. Moon, M. Xu et al., "Efficient and stable solid-state dye-sensitized solar cells based on a high-molarextinction-coefficient sensitizer," Small, vol. 6, no. 2, pp. 319$324,2010$.

[30] I. L. Medintz, M. H. Stewart, S. A. Trammell et al., "Quantum-dot/dopamine bioconjugates function as redox coupled assemblies for in vitro and intracellular $\mathrm{pH}$ sensing," Nature Materials, vol. 9, no. 8, pp. 676-684, 2010.

[31] O. Labeau, P. Tamarat, and B. Lounis, “Temperature dependence of the luminescence lifetime of single CdSe/ZnS quantum dots," Physical Review Letters, vol. 90, no. 25, pp. 25740412574044, 2003.

[32] S. F. Wuister, C. De Mello Donegá, and A. Meijerink, "Influence of thiol capping on the exciton luminescence and decay kinetics of CdTe and CdSe quantum dots," Journal of Physical Chemistry B, vol. 108, no. 45, pp. 17393-17397, 2004.

[33] J. Frenzel, J.-O. Joswig, and G. Seifert, "Optical excitations in cadmium sulfide nanoparticles," Journal of Physical Chemistry C, vol. 111, no. 29, pp. 10761-10770, 2007.

[34] M. Liras, M. Gonzalez-Bejar, and J. C. Scaiano, "On-off QD switch that memorizes past recovery from quenching by diazonium salts," Physical Chemistry Chemical Physics, vol. 12, no. 33, pp. 9757-9762, 2010.

[35] C. A. Leatherdale and M. G. Bawendi, "Observation of solvatochromism in CdSe colloidal quantum dots," Physical Review $B$, vol. 63, no. 16, Article ID 165315, pp. 1-6, 2001.

[36] O. Schmelz, A. Mews, T. Basché, A. Herrmann, and K. Müllen, "Supramolecular complexes from CdSe nanocrystals and organic fluorophors," Langmuir, vol. 17, no. 9, pp. 28612865, 2001.

[37] A. Boulesbaa, A. Issac, D. Stockwell et al., "Ultrafast charge separation at CdS quantum dot/rhodamine B molecule interface," Journal of the American Chemical Society, vol. 129, no. 49, pp. 15132-15133, 2007.

[38] A. Issac, S. Jin, and T. Lian, "Intermittent electron transfer activity from single CdSe/ZnS quantum dots," Journal of the American Chemical Society, vol. 130, no. 34, pp. 11280-11281, 2008.

[39] S. Dayal, R. Królicki, Y. Lou et al., "Femtosecond time-resolved energy transfer from CdSe nanoparticles to phthalocyanines," Applied Physics B, vol. 84, no. 1-2, pp. 309-315, 2006.

[40] E. I. Zen'kevich, E. I. Sagun, A. A. Yarovoi et al., "Photoinduced relaxation processes in complexes based on semiconductor CdSe nanocrystals and organic molecules," Optics and Spectroscopy, vol. 103, no. 6, pp. 958-968, 2007.

[41] A. R. Clapp, I. L. Medintz, B. R. Fisher, G. P. Anderson, and H. Mattoussi, "Can luminescent quantum dots be efficient energy acceptors with organic dye donors?" Journal of the American Chemical Society, vol. 127, no. 4, pp. 1242-1250, 2005.

[42] S. Dayal, Y. Lou, A. C. S. Samia, J. C. Berlin, M. E. Kenney, and C. Burda, "Observation of non-förster-type energy-transfer behavior in quantum dot-phthalocyanine conjugates," Journal of the American Chemical Society, vol. 128, no. 43, pp. 1397413975, 2006.

[43] E. I. Zenkevich, E. I. Zenkevich, and A. A. Yarovoi, "Physics, chemistry and applications of nanostructures," in Reviews and Short Notes to Nanomeeting, V. I. Borisenko, S. V. Gaponenko, and V. S. Gurin, Eds., p. 140, World Scientific, London, UK, 2007.

[44] T. Ren, P. K. Mandal, W. Erker et al., "A simple and versatile route to stable quantum dot-dye hybrids in nonaqueous and aqueous solutions ," Journal of the American Chemical Society, vol. 130, no. 51, p. 17242, 2008.

[45] J. E. Halpert, J. R. Tischler, G. Nair et al., "Electrostatic formation of quantum dot/J-aggregate FRET pairs in solution," Journal of Physical Chemistry C, vol. 113, no. 23, pp. 99869992, 2009.

[46] J. Lee, H. J. Kim, T. Chen et al., "Control of energy transfer to cdte nanowires via conjugated polymer orientation," Journal of Physical Chemistry C, vol. 113, no. 1, pp. 109-116, 2009. 
[47] D. Kowerko, S. Krause, N. Amecke, M. Abdel-Mottaleb, J. Schuster, and C. Von Borczyskowski, "Identification of different donor-acceptor structures via Förster Resonance Energy Transfer (FRET) in quantum-dot-perylene bisimide assemblies," International Journal of Molecular Sciences, vol. 10, no. 12, pp. 5239-5256, 2009.

[48] D. Kowerko, J. Schuster, N. Amecke et al., "FRET and ligand related NON-FRET processes in single quantum dot-perylene bisimide assemblies," Physical Chemistry Chemical Physics, vol. 12, no. 16, pp. 4112-4123, 2010.

[49] C. Burda, T. C. Green, S. Link, and M. A. El-Sayed, "Electron shuttling across the interface of CdSe nanoparticles monitored by femtosecond laser spectroscopy," Journal of Physical Chemistry B, vol. 103, no. 11, pp. 1783-1788, 1999.

[50] M. Sykora, M. A. Petruska, J. Alstrum-Acevedo, I. Bezel, T. J. Meyer, and V. I. Klimov, "Photoinduced charge transfer between CdSe nanocrystal quantum dots and Ru-polypyridine complexes," Journal of the American Chemical Society, vol. 128, no. 31, pp. 9984-9985, 2006.

[51] S. Rakshit and S. Vasudevan, "Spectrally resolved resonance energy transfer from $\mathrm{ZnO}: \mathrm{MgO}$ nanocrystals," Journal of Physical Chemistry C, vol. 113, no. 37, pp. 16424-16431, 2009.

[52] J. Lee, H. J. Kim, T. Chen et al., "Control of energy transfer to cdte nanowires via conjugated polymer orientation," Journal of Physical Chemistry C, vol. 113, no. 1, pp. 109-116, 2009.

[53] M. A. Jhonsi and R. Renganathan, "Investigations on the photoinduced interaction of water soluble thioglycolic acid (TGA) capped CdTe quantum dots with certain porphyrins," Journal of Colloid and Interface Science, vol. 344, no. 2, pp. 596602, 2010.

[54] T. Pons, I. L. Medintz, X. Wang, D. S. English, and H. Mattoussi, "Solution-phase single quantum dot fluorescence resonance energy transfer," Journal of the American Chemical Society, vol. 128, no. 47, pp. 15324-15331, 2006.

[55] A. O. Orlova, M. S. Gubanova, V. G. Maslov et al., "Spektral'no-lyuminestsentnye svoistva kompleksov, obrazovannykh odnoimenno zaryazhennymi cdte kvantovymi tochkami i molekulami tetrasul'foftalotsianina," Optika I Spectroscopiya, vol. 6, no. 108, pp. 975-982, 2010 (Russian).

[56] A. Issac, C. Von Borczyskowski, and F. Cichos, "Correlation between photoluminescence intermittency of CdSe quantum dots and self-trapped states in dielectric media," Physical Review B, vol. 71, Article ID 161302, 2005.

[57] C. Bullen and P. Mulvaney, "The effects of chemisorption on the luminescence of CdSe quantum dots," Langmuir, vol. 22, no. 7, pp. 3007-3013, 2006.

[58] B. Von Holt, S. Kudera, A. Weiss et al., "Ligand exchange of CdSe nanocrystals probed by optical spectroscopy in the visible and mid-IR," Journal of Materials Chemistry, vol. 18, no. 23, pp. 2728-2732, 2008.

[59] R. Koole, P. Schapotschnikow, C. de Mello Donegá, T. J. H. Vlugt, and A. Meijerink, "Time-dependent photoluminescence spectroscopy as a tool to measure the ligand exchange kinetics on a quantum dot surface," ACS Nano, vol. 2, no. 8, pp. 1703-1714, 2008.

[60] X. Ji, D. Copenhaver, C. Sichmeller, and X. Peng, "Ligand bonding and dynamics on colloidal nanocrystals at room temperature: the case of alkylamines on CdSe nanocrystals," Journal of the American Chemical Society, vol. 130, no. 17, pp. 5726-5735, 2008.

[61] A. M. Munro and D. S. Ginger, "Photoluminescence quenching of single CdSe nanocrystals by ligand adsorption," Nano Letters, vol. 8, no. 8, pp. 2585-2590, 2008.
[62] P. Schapotschnikow, B. Hommersom, and T. J. H. Vlugt, "Adsorption and binding of ligands to cdse nanocrystals," Journal of Physical Chemistry C, vol. 113, no. 29, pp. 12690-12698, 2009.

[63] T. Blaudeck, E. I Zenkevich., F. Cichos, and C. von Borczyskowski, "Probing wave functions at semiconductor quantum-dot surfaces by NON-FRET photoluminescence quenching," Journal of Physical Chemistry C, vol. 112, no. 51, pp. 20251-20257, 2008.

[64] É. I. Zen'Kevich, T. Blaudeck, M. Heidernätsch, F. Cichos, and C. Von Borczyskowski, "Effects of electron tunneling and nonresonance quenching of photoluminescence in semiconducting CdSe/ZnS and CdSe nanocrystals by porphyrin molecules in joint complexes," Theoretical and Experimental Chemistry, vol. 45, no. 1, pp. 23-34, 2009.

[65] D. M. Willard, L. L. Carillo, J. Jung, and A. Van Orden, "CdSe$\mathrm{ZnS}$ quantum dots as resonance energy transfer donors in a model protein-protein binding assay," Nano Letters, vol. 1, no. 9, pp. 469-474, 2001.

[66] D. S. Kilin, K. Tsemekhman, O. V. Prezhdo, E. I. Zenkevich, and C. von Borczyskowski, "Ab initio study of exciton transfer dynamics from a core-shell semiconductor quantum dot to a porphyrin-sensitizer," Journal of Photochemistry and Photobiology A, vol. 190, no. 2-3, pp. 342-351, 2007.

[67] J. E. B. Katari, V. L. Colvin, and A. P. Alivisatos, "X-ray photoelectron spectroscopy of CdSe nanocrystals with applications to studies of the nanocrystal surface," Journal of Physical Chemistry, vol. 98, no. 15, pp. 4109-4117, 1994.

[68] F. V. Mikulec, M. Kuno, M. Bennati, D. A. Hall, R. G. Griffin, and M. G. Bawendi, "Organometallic synthesis and spectroscopic characterization of manganese-doped CdSe nanocrystals," Journal of the American Chemical Society, vol. 122, no. 11, pp. 2532-2540, 2000.

[69] W. W. Yu, L. Qu, W. Guo, and X. Peng, "Experimental determination of the extinction coefficient of CdTe, CdSe, and CdS nanocrystals," Chemistry of Materials, vol. 15, no. 14, pp. 2854-2860, 2003.

[70] E. I. Zenkevich, C. Von Borczyskowski, A. M. Shulga, S. Bachilo, U. Rempel, and A. Willert, "Self-assembled nanoscale photomimetic models: structure and related dynamics," Chemical Physics, vol. 275, no. 1-3, pp. 185-209, 2002.

[71] E. I. Zenkevich, C. Von Borczyskowski, and A. M. Shulga, "Structure and excited state properties of multiporphyrin arrays formed by supramolecular design," Journal of Porphyrins and Phthalocyanines, vol. 7, no. 11-12, pp. 731-754, 2003.

[72] E. I. Sagun, E. I. Zenkevich, V. N. Knyukshto, A. M. Shulga, and N. V. Ivashin, "Self-assembling effects and mechanisms of interchromophore interactions in porphyrin pentads," Optika i Spektroskopiya, vol. 108, no. 4, pp. 553-570, 2010.

[73] E. I. Sagun, E. I. Zenkevich, V. N. Knyukshto, and A. M. Shulga, Optika i Spectroskpiya, vol. 110, p. 251, 2011.

[74] E. I. Zen'kevich, A. M. Shul'ga, A. V. Chernook, and G. P. Gurinovich, Journal of Applied Spectroscopy, vol. 45, no. 6, p. 984, 1986.

[75] R. A. Marcus, "Electron transfer reactions in chemistry. Theory and experiment," Reviews of Modern Physics, vol. 65, no. 3, pp. 599-610, 1993.

[76] E. P. Petrov, F. Cichos, and C. Von Borczyskowski, "Intrinsic photophysics of semiconductor nanocrystals in dielectric media: formation of surface states," Journal of Luminescence, vol. 119-120, pp. 412-417, 2006.

[77] E. Zenkevich, T. Blaudeck, M. Abdel-Mottaleb, F. Cichos, A. Shulga, and C. Von Borczyskowski, "Photophysical properties 
of self-aggregated porphyrin: semiconductor nanoassemblies," International Journal of Photoenergy, vol. 2006, Article ID 90242, 7 pages, 2006.

[78] R. K. Sen, E. Yeager, and W. E. O’Grady, "Theory of charge transfer at electrochemical interfaces," Annual Review of Physical Chemistry, vol. 26, p. 287, 1975.

[79] H. Lüth, Surfaces and Interfaces of Solid Materials, Springer, Berlin, Germany, 3rd edition, 1995.

[80] F. Cichos, C. von Borczyskowski, and M. Orrit, "Power-law intermittency of single emitters," Current Opinion in Colloid and Interface Science, vol. 12, no. 6, pp. 272-284, 2007.

[81] B. O. Dabbousi, J. Rodriguez-Viejo, F. V. Mikulec et al., "(CdSe $) \mathrm{ZnS}$ core-shell quantum dots: synthesis and characterization of a size series of highly luminescent nanocrystallites," Journal of Physical Chemistry B, vol. 101, no. 46, pp. 9463 9475, 1997.

[82] J. W. Haus, H. S. Zhou, I. Honma, and H. Komiyama, "Quantum confinement in semiconductor heterostructure nanometer-size particles," Physical Review B, vol. 47, no. 3, pp. 1359-1365, 1993.

[83] http://www.tu-chemnitz.de/physik/THUS/tmp/OSP/org/ opensourcephysics/numerics/ODEMultistepSolver.html.

[84] T. S. Marshall and T. M. Wilson, "Electronic structure of freestanding (ZnSe)m(ZnS)n (001) strained-layer superlattices," Physical Review B, vol. 50, no. 20, pp. 15034-15046, 1994.

[85] S. Nomura and T. Kobayashi, "Nonparabolicity of the conduction band in CdSe and CdSxSe1-x semiconductor microcrystallites," Solid State Communications, vol. 78, no. 8, pp. 677-680, 1991.

[86] M. Nirmal, B. O. Dabbousi, M. G. Bawendi et al., "Fluorescence intermittency in single cadmium selenide nanocrystals," Nature, vol. 383, no. 6603, pp. 802-804, 1996.

[87] G. Schlegel, J. Bohnenberger, I. Potapova, and A. Mews, "Fluorescence decay time of single semiconductor nanocrystals," Physical Review Letters, vol. 88, no. 13, Article ID 137401, pp. $1-4,2002$.

[88] E. Zenkevich, F. Cichos, A. Shulga, E. P. Petrov, T. Blaudeck, and C. Von Borczyskowski, "Nanoassemblies designed from semiconductor quantum dots and molecular arrays," Journal of Physical Chemistry B, vol. 109, no. 18, pp. 8679-8692, 2005. 


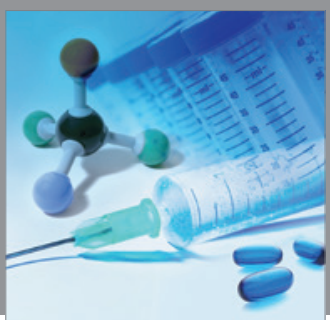

International Journal of

Medicinal Chemistry

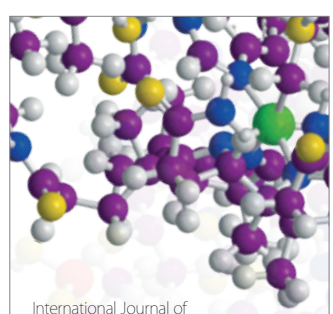

Carbohydrate Chemistry

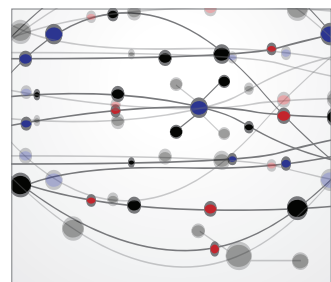

The Scientific World Journal
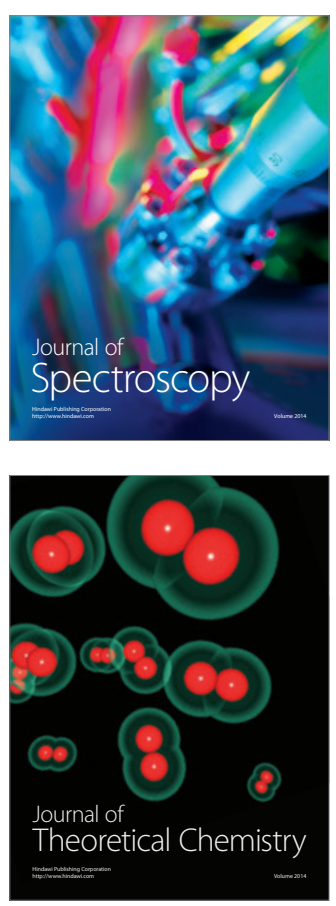
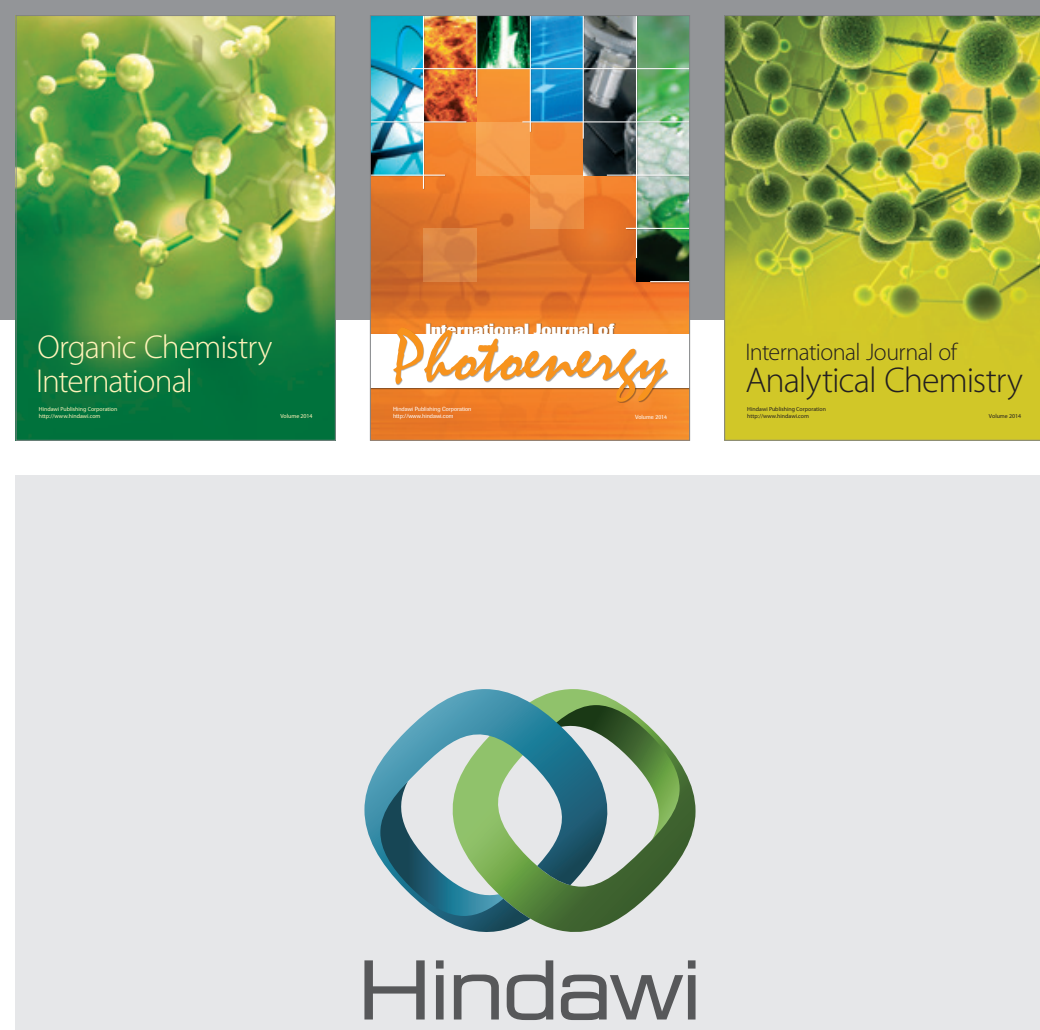

Submit your manuscripts at

http://www.hindawi.com
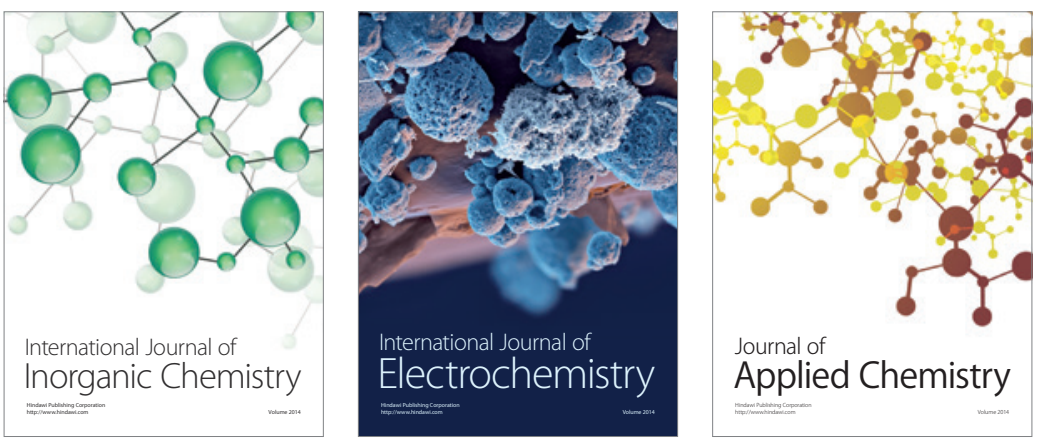

Journal of

Applied Chemistry
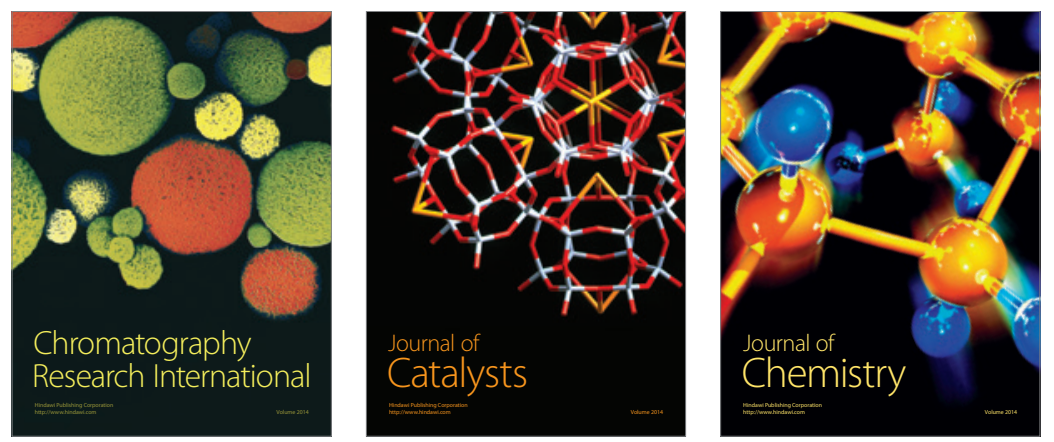
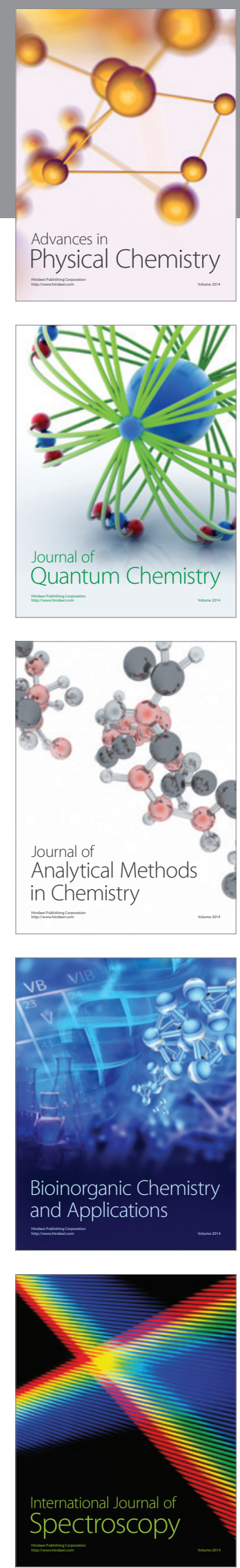